\title{
Neurokinin B regulates reproduction via inhibition of kisspeptin in a teleost, the striped bass
}

\author{
Nilli Zmora', Ten-Tsao Wong', John Stubblefield', Berta Levavi-Sivan² and \\ Yonathan Zohar ${ }^{1}$ \\ 1Department of Marine Biotechnology, Institute of Marine and Environmental Technology, University of \\ Maryland Baltimore County, Baltimore, Maryland, USA \\ 2Department of Animal Sciences, Faculty of Agriculture, Food and Environment, The Hebrew University, \\ Rehobot, Israel
}

Correspondence should be addressed to $\mathrm{N}$ Zmora or Y Zohar Email nzmora@umbc.edu or zohar@umbc.edu

\begin{abstract}
Kisspeptin and neurokinin B (NKB) are neuropeptides co-expressed in the mammalian hypothalamus and coordinately control GnRH signaling. We have found that $\mathrm{Nkb}$ and kisspeptin neurons are distinct in the teleost, striped bass (STB) and capitalized on this phenomenon to study the mode of action of $\mathrm{Nkb}$ and its related neuropeptide- $\mathrm{F}$ (Nkf), both of which are encoded by the tac3 gene. In vitro brain slices and in vivo administration studies revealed that $\mathrm{Nkb} / \mathrm{f}$ consistently downregulated $k i s s 2$, whereas antagonist (AntD) administration restored this effect. Overall, a minor effect was noted on gnrh1 expression, whereas Gnrh 1 content in the pituitaries was reduced after $\mathrm{Nkb} / \mathrm{f}$ treatment and increased with AntD. Concomitantly, immunostaining demonstrated that hypothalamic Nkb neurons border and densely innervate the largest kiss2 neuronal population in the hypothalamus, which also coexpresses Nkb receptor. No expression of Nkb receptor or Nkb neuronal projections was detected near/in Gnrh1 soma in the preoptic area. At the level of the pituitary, however, the picture was more complex: both $\mathrm{Nkb} / \mathrm{f}$ and AntD upregulated $/ \mathrm{h} b$ and $\mathrm{fsh} b$ expression and Lh secretion in vivo. Together with the stimulatory effect of $\mathrm{Nkb/f}$ on Lh/Fsh secretion from pituitary cells, in vitro, this may indicate an additional independent action of $\mathrm{Nkb} / \mathrm{f}$ within the pituitary, in which the hypothalamic pathway is more dominant. The current study demonstrates that $\mathrm{Nkb/f}$ utilizes multiple pathways to regulate reproduction in the STB and that in the brain, $\mathrm{Nkb}$ mainly acts as a negative modulator of kiss2 to regulate the release of Gnrh1.
\end{abstract}
Key Words
- neuroanatomy
- reproductive axis
- neuropeptides
- Gnrh
- gonadotropes

\section{Introduction}

Reproduction is a fundamental process, tightly regulated by central and peripheral factors at the brain/ hypothalamus, pituitary and gonad (HPG) levels. The principal components of the HPG axis have long been described in many vertebrate species, for which the hypothalamic gonadotropin-releasing-hormone (GnRH) is pivotal to the regulation of reproduction. During the past decade, numerous known and novel neuropeptides have been implicated in the upstream control of GnRH neurons and gonadotropes in the pituitary.

Neurokinin B (NKB) has recently emerged as an important component of the network controlling reproductive function. Similar to the KISS1/GPR54 system, the crucial reproductive role of NKB was discovered via a

Published by Bioscientifica Ltd 
null mutation in the gene encoding NKB (TAC3 in humans and Tac2 in rodents) or its receptor (TAC3r) encoded by Tac3r gene, in hypogonadotropic hypogonadal human patients and infertile mice (Topaloglu et al. 2009, Yang et al. 2012). In mammals, NKB is coexpressed with dynorphin-A in a subset of Kiss1 neurons in the arcuate nucleus (ARC), also termed KNDy neurons (Goodman et al. 2007, Navarro et al. 2009, Lehman et al. 2010, Wakabayashi et al . 2010). Together, these three neuropeptides are believed to generate and pace the GnRH pulses via a sex steroiddependent mechanism (Navarro 2012). Although the stimulatory effect of KISS1 (Navarro et al. 2009, 2011a, 2012, Wakabayashi et al. 2010, Garcia-Galiano et al. 2012) and the inhibitory effect of dynorphin-A (Gallo 1990, Grachev et al. 2014) on the GnRH pulse are widely acknowledged, the effect of NKB remains controversial as studies have reported both NKB inhibition and stimulation of the reproductive axis (Sandoval-Guzman \& Rance 2004, Navarro et al. 2011a, Garcia-Galiano et al. 2012, Grachev et al. 2012a, Kinsey-Jones et al. 2012, RuizPino et al. 2014). However, despite the contradictory findings in mammals (Krajewski et al. 2005, Todman et al. 2005, Burke et al. 2006a, Amsteldam et al. 2009, Navarro et al. 2011b), the emerging notion is that NKB does not act directly on GnRH neurons (Navarro 2012). This is supported by the observation that senktide (NKB agonist) treatment did not trigger action potentials in GFPlabeled GnRH neurons of mouse (Navarro et al. 2011b). A growing body of recent data from GPR54-knockout mice (Garcia-Galiano et al. 2012), rats (Grachev et al. 2012b) and monkeys (Ramaswamy et al. 2011) suggests that NKB affects the reproductive axis via kisspeptin and that kisspeptin is essential for NKB signaling.

Even more confusing are the sparse reports on the involvement of $\mathrm{NKB}$ in regulating reproduction in teleosts. The first indication that Nkb is widely expressed in fish species and has a stimulatory reproductive effect was shown in zebrafish and goldfish (Ogawa et al. 2012, Qi et al. 2015). Teleost tac3 gene encodes two peptides, Nkb- and Nkb-related peptide, also termed neurokinin F (Nkf) (Biran et al. 2012). Subsequent studies have shown that Nkb acts at the level of the pituitary (Biran et al. 2014, $\mathrm{Hu}$ et al. 2014), but very little is known regarding the effect of $\mathrm{Nkb}$ at the level of the brain and its relationships with Gnrh and kisspeptin neurons in the context of reproduction in teleosts.

In this study, we localized Tac3 and Tac3r neurons in male striped bass (STB), Morone saxatilis, reproductively relevant brain regions and showed that, unlike in mammals, Tac3 is not localized in kisspeptin neurons. This feature helped answer questions regarding the interactions between $\mathrm{Nkb}$ and kisspeptin neurons. The relationships of Tac3, kisspeptin and Gnrh1 neurons were examined neuro-anatomically. The effect of $\mathrm{Nkb}$ and Nkf on Gnrh1 and kisspeptin was studied both in vivo and in vitro. Our results establish the role of Nkb as a direct negative modulator of Kiss2, but not of Gnrh1, in the hypothalamus.

\section{Materials and methods}

\section{Animals}

Animal maintenance and experimental procedures were approved by the Institutional Animal Care and Use Committee of the University of Maryland School of Medicine IACUC \#0613018 and \#0516021. STB were obtained as juveniles from the Maryland Department of Natural Resources and maintained at ambient conditions in a $2.5 \mathrm{~m}^{3}$ tank supplied with constant exchange of artificial $8-10$ ppt seawater. Fish were anesthetized for $\sim 10 \mathrm{~min}$ in water containing $200 \mathrm{mg} / \mathrm{L}$ tricaine methanesulfonate (MS-222) (Sigma) before killing or treatment. Treated fish were immediately transferred to clean water for recovery.

\section{Peptides}

The full cDNA of tac3 and tac $3 r$ genes of the STB were cloned from STB brain cDNA library (Supplementary material 1 , see section on supplementary data given at the end of this article) and deposited in GenBank (accession \#: KT361626 and KT361627). Only one variant for each gene was detected. The deduced STB Nkb ((pGLU) MHDIFIGLM-NH $\mathrm{N}_{2}$ ) and neurokinin-related peptide (Nkf: YSDLDYDSFVGLM-NH ${ }_{2}$ ) and mammalian $\mathrm{Nkb}$ antagonists (AntD: (D-Pro2, D-Trp6,8, Nleu10)-neurokinin $\mathrm{B}$ or DPDTNLE-NB: (Asp-D-Pro-His-Asp-Phe-D-Trp-ValD-Trp-Leu-Nle- $\mathrm{NH}_{2}$ )) (Jacoby et al. 1986) peptides were synthesized at $>95 \%$ purity (Genscript). The authenticity of the peptides was confirmed by mass spectrometry. Other screened antagonists: SB222200 was obtained from Santa Cruz Biotechnology and GR159897 from Tocris Biosciences. R486 (Asp-Ser-Phe-Trp-P-Ala-Leu-Met-NH2) (Almeida et al. 2004), neurokinin A (NKA) and substance P (SP) and NK1 antagonist, 3,5-bis(trifluoromethyl)benzyl $\mathrm{N}$-acetyltryptophan were purchased from Sigma. 


\section{Receptor activation and antagonist selection using in vitro luciferase reporter gene assays}

To generate the activation profiles of the neurokinin $\mathrm{B}$ receptor (Tac3r) by Nkb and Nkf, we employed a luciferase (LUC) reporter gene assay using LUC transcriptionally regulated by either a serum response element (SRE; Invitrogen) or a cyclic AMP (cAMP) response element (CRE; Invitrogen). STB tac3r was cloned into pcDNA3.1 expression vector (Zeo; Invitrogen) driven by the cytomegalovirus (CMV) promoter. Transient transfection, cell procedures and stimulation protocols followed the procedures previously described (Deoraj et al. 2000, Alok et al. 2001, Levavi-Sivan et al. 2005, 2010, Biran et al . 2008). COS7 cells were co-transfected with tac3r (30 ng/ well), a reporter plasmid (30 ng/well), and pCMV-Renilla luciferase as transfection control (Promega, $0.03 \mathrm{ng} /$ well) using FuGENE 6.0 reagent (Promega) for $24-48 \mathrm{~h}$. The cells were serum deprived for $18 \mathrm{~h}$, stimulated with different concentrations of either $\mathrm{Nkb}$ or $\mathrm{Nkf}$ (with or without the tested potential antagonists) for $6 \mathrm{~h}$ in a HEPES-modified DMEM supplemented with $0.5 \%$ BSA, and then harvested and analyzed. Cell lysates were assayed for both firefly and Renilla luciferase activity using the dual-luciferase reporter assay kit (Promega). Nkb and Nkf peptides were used to generate an initial dose-response and to determine the signal transduction pathway in $10 \times$ serial dilutions from $1 \mathrm{fM}$ to $10 \mu \mathrm{M}$ (in triplicate). $\mathrm{EC}_{50}$ values were calculated via analysis by a 3-parameter response curve formula using GraphPad Prism software from 3 individual trials.

Peptides and non-peptide molecules known to antagonize mammalian NK3R were tested for their ability to antagonize Tac3r of the STB, which was activated with a fixed dose of $1 \mathrm{nM} \mathrm{Nkb}$ or $0.1 \mathrm{nM}$ Nkf combined with graded doses of the antagonists. The antagonists were added $\sim 30$ min prior to the addition of $\mathrm{Nkb} / \mathrm{f}$ peptides. $\mathrm{IC}_{50}$ values were extrapolated by Sigmoidal 4PL analysis using GraphPad Prism software.

\section{Brain and pituitary incubation assays in vitro}

$\mathrm{Nkb}, \mathrm{Nkf}$ and AntD activities were further examined in STB brains and pituitaries using brain slices and primary pituitary culture assays, respectively (Klenke 2006). Brains and pituitaries of precociously spermiating mature males collected during the reproductive season (February through March) were used, mainly due to the relatively long period of this stage that allowed the conduction of multiple rounds of trials.
Brain slices Whole brains were sliced to $300 \mu \mathrm{m}$ slices using a Mcllwain Tissue Slicer. Slices were placed in $74 \mu \mathrm{m}$ mesh inserts in a six-well plate, containing $4 \mathrm{~mL}$ of glucose DMEM at $\mathrm{pH} 7.44$, followed by $3 \times 1$-h washes, and then incubated with medium containing the tested peptides for six hours at $20^{\circ} \mathrm{C}$ with gentle agitation. Tissues and medium were then stored frozen until further analysis. RNA was extracted from the brains, and its quality and integrity were verified in roughly $25 \%$ of the samples via denaturing paraformaldehyde agarose gel electrophoresis. cDNAs were prepared and followed by quantitative RT-PCR as described below.

Primary pituitary culture The culture procedure was carried out under aseptic conditions. Pituitaries were grossly chopped and cells were dispersed with $1 \mathrm{~mL}$ $0.25 \%$ trypsin-EDTA in DMEM (Gibco) for $5 \mathrm{~min}$ at room temperature, during which the medium was run through a $1 \mathrm{~mL}$ syringe equipped with 18- or 21-gauge needles. The reaction was stopped by the addition of $1 \mathrm{~mL}$ fetal calf serum. The cells were counted using a hemocytometer and populated at a density of 50,000 or 25,000 cells per well in 24 or 48 -well plates, respectively. The cells were incubated for three days at $20^{\circ} \mathrm{C}$ and then incubated with serum-free medium (with $0.5 \% \mathrm{BSA}$ ) containing the tested peptides for $24 \mathrm{~h}$. The cells and mediums were collected separately and stored frozen until analysis.

\section{Treatment of male STB with Nkb, Nkf and AntD in vivo}

Nkb and Nkf injection study Precociously spermiating males sampled in mid-December $(n=7$; average body weight \pm S.D.: $683 \pm 153 \mathrm{~g}$; gonad somatic index $(G S I)=6.6$ ) were treated with single intramuscular injection (between the gills cover and the peritoneum) of $\mathrm{Nkb}$ or Nkf peptides in saline at doses of 0,10 or $100 \mu \mathrm{g} / \mathrm{kg}$ body weight (BW). Blood was sampled immediately before and at 2, 4 and $24 \mathrm{~h}$ after injection. Fish were killed by decapitation after $24 \mathrm{~h}$, and brains, pituitaries and gonads were sampled for gene expression and ELISA assays of various components along the reproductive axis and for gonadal histology.

Nkb and Kiss antagonists treatment studies Spermiating males at the time of spawning in midApril, $(n=8$; average BW \pm S.D.: $=355 \pm 110 \mathrm{~g} ; \mathrm{GSI}=10.2)$ were injected intramuscularly with poly(D,L-lactide-coglycolide) 50:50 (PLGA, Sigma) (Mylonas \& Zohar 2001) slow-release microspheres containing AntD at doses of 0 ,

Published by Bioscientifica Ltd. 
5 or $50 \mu \mathrm{g} / \mathrm{kg}$ BW. The experiment was concluded 10 days after implantation. (2) A similar 9-day experiment was conducted with microspheres containing the Kisspeptin antagonists, pep 234 or pep 359, at doses of 0,5 or $30 \mu \mathrm{g} / \mathrm{kg}$ BW (Zmora et al. 2015).

Blood was sampled immediately prior to implantation and at the trial termination for Lh and Fsh plasma levels measurements. Sperm from each fish was collected at the end of the experiment to determine milt volume and weight. Brains and pituitaries were collected and frozen.

\section{Hormones and gene transcript measurements}

Lh levels in the plasma were measured using ELISA as previously described (Mananos et al. 1997). Levels of Fsh were measured using a specific ELISA developed for tilapia Fsh (Aizen et al. 2007) and validated for use in

Table 1 Gene-specific primers.

\begin{tabular}{|c|c|c|c|}
\hline Primer & Sequence $5^{\prime}-3^{\prime}$ & Direction & $\begin{array}{l}\text { GeneBank } \\
\text { accession \# }\end{array}$ \\
\hline Tac3F & $\begin{array}{l}\text { GATCCTGAACGGATCT- } \\
\text { CACTGCA }\end{array}$ & $\mathrm{F}$ & KT361626 \\
\hline Tac3R & $\begin{array}{l}\text { CAGCTGGTAGATCATT- } \\
\text { TAGTCGTCAG }\end{array}$ & $\mathrm{R}$ & \\
\hline Tac3recF1 & $\begin{array}{l}\text { TGTGGACAGGTACATGGC- } \\
\text { CATCAT }\end{array}$ & $\mathrm{F}$ & KT361627 \\
\hline Tac3recF2 & $\begin{array}{l}\text { CCTGAAGCCTCGTCT- } \\
\text { GTCTGC }\end{array}$ & $\mathrm{F}$ & \\
\hline Tac3recR & $\begin{array}{l}\text { CCAGGCCAGGTAG- } \\
\text { CAGAGG }\end{array}$ & $\mathrm{F}$ & \\
\hline TAQgnrh1F & GGAACGGACGGCCTCTCA & $\mathrm{F}$ & AF056314 \\
\hline TAQgnrh1R & GTGGGAAGCCCCCGACTA & $\mathrm{R}$ & \\
\hline TAQFSHbF & TGGCCTCACCGAGGTCAT & $\mathrm{F}$ & L35070 \\
\hline TAQFSHbR & $\begin{array}{l}\text { CAGTCTCCGTTACA- } \\
\text { GATTCTCTGTTC }\end{array}$ & $\mathrm{R}$ & \\
\hline TAQLHbF & CTTGGGACAGCCCTCCTTCT & $\mathrm{F}$ & L35096 \\
\hline TAQLHbR & $\begin{array}{l}\text { CTGGGAGCCACATCT- } \\
\text { GACAT }\end{array}$ & $\mathrm{R}$ & \\
\hline TAQTac3F & $\begin{array}{l}\text { TGTCGATGCAAACGCTG- } \\
\text { TAGAGTC }\end{array}$ & $\mathrm{F}$ & KT361626 \\
\hline TAQTac3R & $\begin{array}{l}\text { CAGGGACCATTATCAG- } \\
\text { GCTCTGAG }\end{array}$ & $\mathrm{R}$ & \\
\hline TAQKiss1F & $\begin{array}{l}\text { CACGATGCCACGACT- } \\
\text { CATTG }\end{array}$ & $\mathrm{F}$ & GU351864 \\
\hline TAQKiss1R & $\begin{array}{l}\text { CTGATCTTTACTGTGG- } \\
\text { TAGCTGGATTT }\end{array}$ & $\mathrm{R}$ & \\
\hline TAQKiss2F & CGGCAGCTCCTGTGCAA & $\mathrm{F}$ & GU351865 \\
\hline TAQKiss2R & $\begin{array}{l}\text { GCCCTTCTGTAAATGTAGC- } \\
\text { GTTTC }\end{array}$ & $\mathrm{R}$ & \\
\hline TAQEF1 $\alpha F$ & $\begin{array}{l}\text { GGAGTGAAGCAGCT- } \\
\text { CATCGT }\end{array}$ & $\mathrm{F}$ & AJ866727 \\
\hline TAQEF1 $\alpha R$ & GCGGGCCTGGCTGTAAG & $\mathrm{R}$ & \\
\hline TAQ18SF & $\begin{array}{l}\text { ACCACCCACAGAATC- } \\
\text { GAGAAA }\end{array}$ & $\mathrm{F}$ & AF147741 \\
\hline TAQ18SR & GCCTGCGGCTTAATTTGACT & $\mathrm{R}$ & \\
\hline
\end{tabular}

http://joe.endocrinology-journals.org DOI: $10.1530 / J O E-16-0575$

(C) 2017 Society for Endocrinology Printed in Great Britain
STB (Zmora et al. 2014). Gnrh decapeptide levels were measured using ELISA (Holland et al. 1998, Zmora et al. 2014, 2015). 11-Ketotestosterone (11-KT) levels in the plasma were measured using 11-KT EIA kit (Cayman Chemicals) according to the manufacturer's protocol. Plasma samples of spermiating males were diluted 1:50 in assay buffer.

Brain or pituitary total RNA $(1 \mu \mathrm{g})$ was reversetranscribed by QuantiTect-RT kit (Qiagen). Real-time PCR was performed on cDNA (50 ng for gnrh, tac3, kiss1 and kiss2, $10 \mathrm{ng}$ for $f s h b$ and $5 \mathrm{ng}$ for $\mathrm{lhb}$ ) using SYBR Green PCR mix (Applied Biosystems) in duplicate, with $0.1 \mu \mathrm{M}$ gene-specific primers (Table 1). $C_{\mathrm{T}}$ values of each sample were normalized against the levels of eef1a1l1 RNA amplified from $5 \mathrm{ng}$ cDNA alongside a cDNA standard curve. eef1a1l1 is commonly used as the primary internal control gene as it typically provides less variable results. However, when more than 1-2 $C_{\mathrm{T}}$ difference was obtained, $18 \mathrm{~S}$ ribosomal RNA (on $0.05 \mathrm{ng}$ cDNA) was also measured to confirm the difference (Tang et al. 2007). Amplification reactions were carried out at $95^{\circ} \mathrm{C}$ for $10 \mathrm{~min}, 40$ cycles of $95^{\circ} \mathrm{C}$ for $15 \mathrm{~s}$ and $60^{\circ} \mathrm{C}$ for $1 \mathrm{~min}$. Proper and specific amplification was verified using gel electrophoresis and by the dissociation curve of the primer sets. In each run, two negative water controls and a no-RT control were also included.

\section{In situ hybridization and immunohistochemistry}

Brains of precociously spermiating males were removed and fixed in buffered $4 \%$ paraformaldehyde and cryoprotected in $15 \%$ sucrose overnight at $4^{\circ} \mathrm{C}$ and embedded in Tissue Tek OCT (Electron Microscopy Sciences). Sections of $12 \mu \mathrm{m}$ were mounted onto Plus glass slides and stored at $-80^{\circ} \mathrm{C}$. In situ hybridization (ISH) and immunohistochemistry (IHC) were conducted using a Tyramide Signal Amplification Kit (TSA, Perkin Elmer) as described earlier (Zmora et al. 2012, 2014). AntiDig HRP (Roche) was used to detect Dig-labeled probe encompassing the entire coding region of each gene. HRP activity between the different stainings was quenched with $0.2 \mathrm{M} \mathrm{HCl}$ for $10 \mathrm{~min}$. Anti-Kiss2, anti-seabass GnRH1associated peptide (GAP) (Gonzalez-Martinez et al. 2002, Zmora et al. 2002, 2012) primary serums, as well as the goat anti-rabbit horseradish peroxidase secondary antibody (Lonza, USA), were all diluted 1:1000. Antimammalian NKB (Phoenix Pharmaceuticals, Inc, cat\# H-046-26) were diluted 1:100. Sense tac3 RNA and anti$\mathrm{NKB}$ was preadsorbed with STB Nkb, and Nkf produced no signal (Supplementary Fig. 2).

Published by Bioscientifica Ltd 


\section{Statistical analysis}

Statistical analyses were performed by one-way ANOVA and Tukey's post hoc test for multiple comparisons, using Instat3 (GraphPad). Lh and Fsh plasma levels statistical analysis included one-way ANOVA, or two-way ANOVA for repeated measures, followed by Tukey HSD. Statistical difference was accepted when $P \leq 0.05$.

\section{Results}

\section{Nkb and Nkf activation of Tac3r and inhibition by $\mathrm{Nkb}$ antagonist}

As a first step, dose-response activation curves of Tac3r by Nkb and Nkf were generated via SRE or CRE, responsive elements that drive the PKC and PKA pathways, respectively, and ultimately transcribe the firefly luciferase gene. The PKA/CRE and PKC/SRE reporter systems both generated dose-response curves, albeit with different activation capacities for each ligand. Using the
PKA pathway, Nkb was $\sim 4.5$ times more potent than Nkf, having an $\mathrm{EC}_{50}$ value of $3.5 \mathrm{pM}$ vs an $\mathrm{EC}_{50}$ of $76 \mathrm{pM}$ for NKF $(n=3)$ (Fig. 1A). Using the PKC pathway, Nkb and Nkf showed similar $\mathrm{EC}_{50}$ values of $4.6 \mathrm{pM}$ and $4.3 \mathrm{pM}$, respectively $(n=3)$ (Fig. 1B). The maximal activation level mediated by PKA/CRE was 2 times higher than that of the PKC/SRE, suggesting that PKA is the dominant pathway for Nkb. Based on the $\mathrm{EC}_{50}$ values, Tac3r showed a 4-100 times higher preference to Nkb over NKA and SP $(n=2)$ (Fig. 1C and D).

Six different neurokinin antagonists were tested by combining serial doses of each antagonist with $1 \mathrm{nM} \mathrm{Nkb}$ or Nkf (Supplementary Fig. 1 depicts the five antagonists that did not exhibit antagonistic activity). Of the six antagonists, only the peptide Asp-dPro-His-Asp-PhedTrp-Val-dTrp-Leu-Nle-NH2 (AntD) displayed a clear antagonistic activity. Starting at a dose of $10 \mathrm{pM}$, AntD reduced the activation of $1 \mathrm{nM} \mathrm{Nkb}$ by $75 \%$ and a starting dose of $1 \mathrm{nM}$ significantly reduced that of $0.1 \mathrm{nM} \mathrm{Nkf}$ by 40\% (n=3) (Fig. 1E and F).
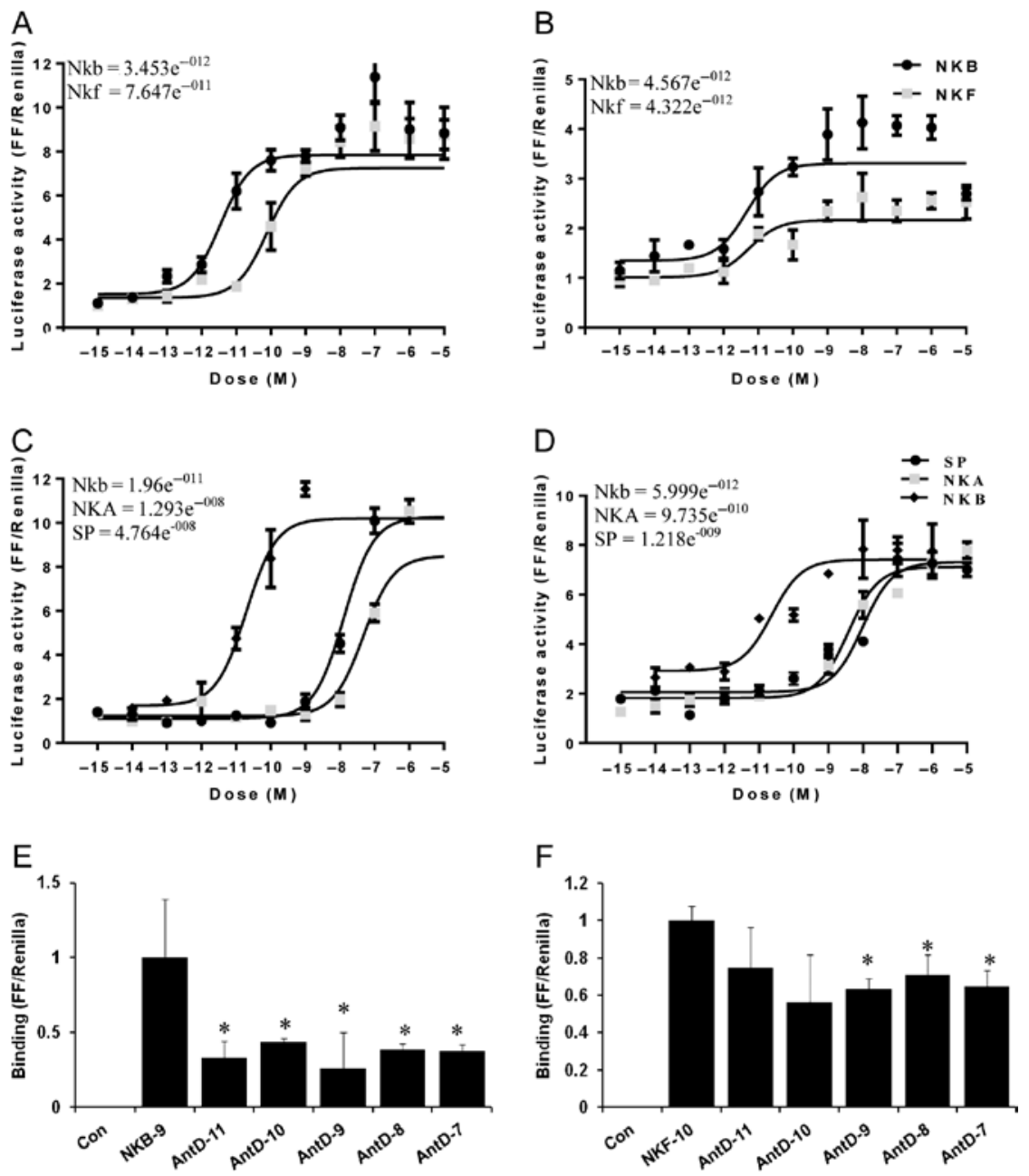

\begin{abstract}
Figure 1
$\mathrm{Nkb}$ and $\mathrm{Nkf}$ activation of $\mathrm{Tac} 3 \mathrm{r}$ and inhibition by AntD. Activation studies were performed using COS7 cells expressing STB Tac3r. Activation of Tac3r by serial concentrations of $\mathrm{Nkb}$ (black circles) and Nkf (grey squares) using (A) the PKA signal transduction pathway and (B) PKC signal transduction pathway. Activation profiles of $\mathrm{Nkb}$ (black diamond), NKA (grey square) and substance $\mathrm{P}$ (SP, black circles) using the (C) PKA signal transduction pathway and (D) PKC signal transduction pathway. The effect of AntD, at concentrations from $10 \mathrm{pM}$ to $100 \mathrm{nM}$, on the activation by (E) $1 \mathrm{nM} \mathrm{Nkb}$ or (F) $0.1 \mathrm{nM} \mathrm{Nkf} \mathrm{using}$ the PKA pathway. All treatments but the controls (no added peptides) contained the specified concentration of either $\mathrm{Nkb}$ or Nkf, with or without the added antagonist. Results are presented as mean \pm S.E.M. of the relative activity of firefly luciferase (FF) vs Renilla luciferase (Renilla). Statistical difference was accepted when $P \leq 0.05$ compared to kisspeptin treatment alone. ${ }^{*} P \leq 0.05$.
\end{abstract}


The effect of $\mathbf{N k b}$ and $\mathbf{N k f}$ on the expression of reproduction-related neuropeptides and gonadotropins in vivo

The effect of a single injection of $\mathrm{Nkb}$ and $\mathrm{Nkf}$ on reproduction-related factors along the HPG in precociously spermiating males (mid-December) was examined. Although $\mathrm{Nkb}$ and Nkf peptides reduced kiss1 and kiss2 mRNA levels by $40-70 \%$ of control (Fig. 2C and D), the effect of Nkf at $100 \mu \mathrm{g} / \mathrm{kg}$ BW was not significant. gnrh1 mRNA levels did not change after the treatments (Fig. 2A), but Gnrh1 pituitary content was significantly reduced by $10 \mu \mathrm{g} / \mathrm{kg}$ BW $\mathrm{Nkb}$ and more profoundly ( $75 \%$ reduction) by both doses of Nkf (Fig. 2B). Nkb at the two doses upregulated $\mathrm{lhb}$ by $\sim 250 \%$, whereas Nkf upregulated the levels of $f s h b$ by $350-400 \%$ of control (Fig. 2E). Plasma Lh levels in the control group at 2, 4 and $24 \mathrm{~h}$ after treatment were significantly lower than those of 0 time point $(10: 00 \mathrm{~h}$, probably due to diurnal changes, as seen earlier (Zmora et al. 2012)) and Nkb/Nkf treatment prevented this decrease (Fig. 2F), whereas Fsh levels were unchanged (Supplementary Fig. 3).
The effect of $\mathbf{N k b}$ and $\mathrm{Nkf}$ on the expression of reproduction-related neuropeptides in the brain, in vitro

Two sets of experiments were conducted on precociously spermiating males. In the first set, whole brain slices were incubated with graded doses of $\mathrm{Nkb}$ or $\mathrm{Nkf}$ (from $10 \mathrm{pM}$ to $10 \mathrm{nM})$, and in the second, $10 \mathrm{nM}$ AntD was co-incubated with $10 \mathrm{nM} \mathrm{Nkb}$ or Nkf. The effect of Nkb, Nkf and AntD, alone or in combination, was determined via qPCR. gnrh1: Of the 4 tested doses, only the higher dose of $10 \mathrm{nM} \mathrm{Nkb}$ and $\mathrm{Nkf}$ upregulated the expression of gnrh 1 by $300 \%$ and $180 \%$ of the control levels, respectively (Fig. 3A). In the second experiment, no such increase was obtained with $10 \mathrm{nM} \mathrm{Nkb}$ or Nkf, with or without AntD (Fig. 3B). kiss2 and kiss1: $\mathrm{Nkb}$ and Nkf downregulated kiss2 expression to $40-50 \%$ of control, starting at a dose as low as $10 \mathrm{pM}$ (Fig. 3C). Nkb downregulated kiss1 mRNA levels starting at $100 \mathrm{pM}$. The effect of Nkf on kiss 1 did not produce a typical dose-response (Fig. 3E). AntD restored the decreased mRNA levels of kiss 2 when incubated with $\mathrm{Nkb}$ or Nkf (Fig. 3D). No change in kiss1 mRNA levels was noted in the second experiment (Fig. 3F). AntD alone had no effect on the expression of either kisspeptin form.
A
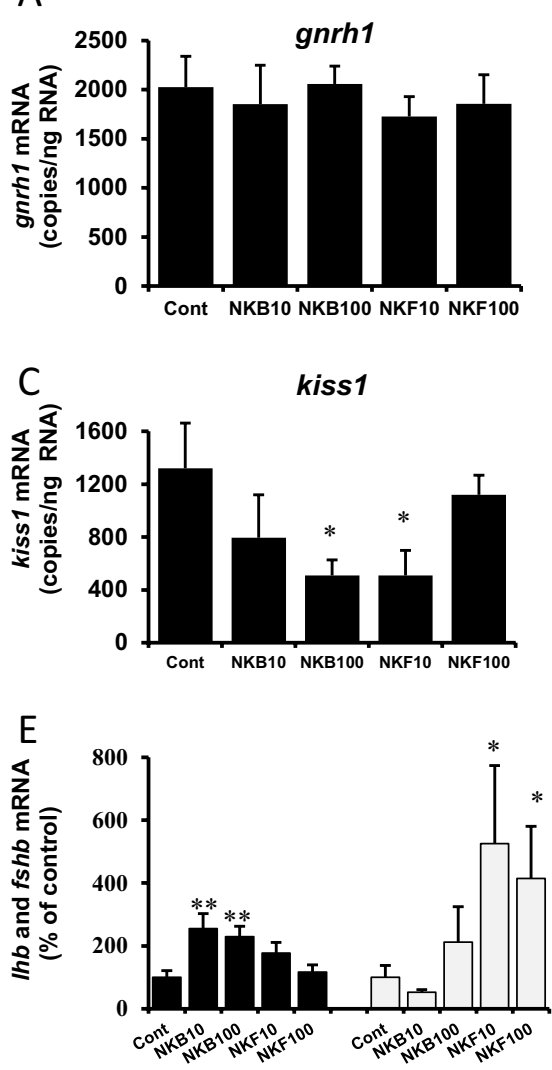

B

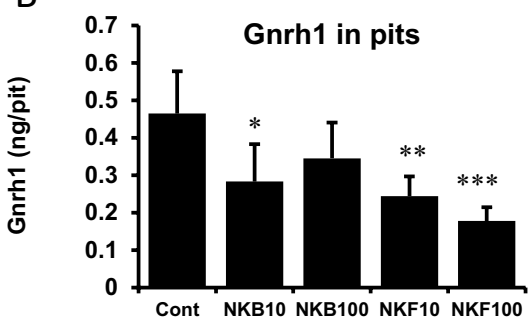

kiss2
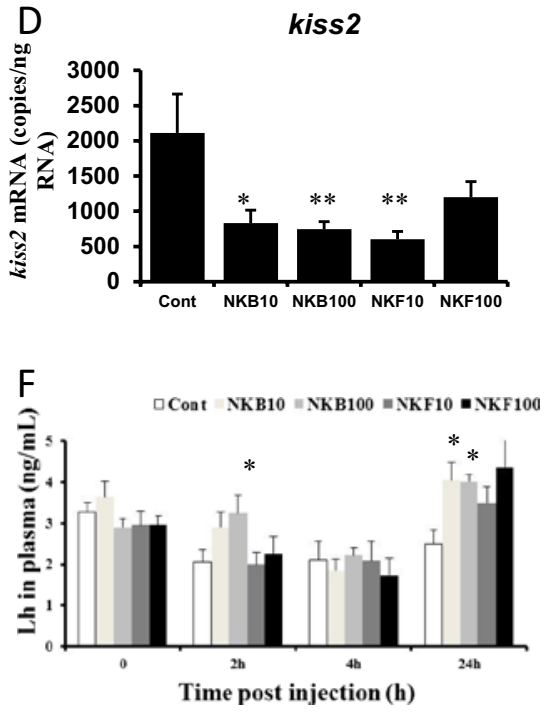

Figure 2

The effect of single injection of $\mathrm{Nkb}$ and $\mathrm{Nkf}$ on neuropeptides and gonadotropins in vivo. $\mathrm{Nkb}$ and $\mathrm{Nkf}$ peptides at doses of 0 (Cont), 10 or $100 \mu \mathrm{g} / \mathrm{BW}$ were injected into precociously spermiating males intraperitoneally ( $n=7$ per group). Samples were taken $24 \mathrm{~h}$ after injection ( $A, B, C, D$ and E). Transcript levels in the brains were measured using qRT-PCR of (A) gnrh1, (C) kiss1 and (D) kiss2. (B) Gnrh1 decapeptide content in the pituitaries of treated males was measured using ELISA. (E) Transcript levels of $/ \mathrm{h}$ (black bars) and fsh (white bars) in the pituitaries. (F) Lh levels in the blood sampled immediately prior to injection and 2, 4 and $24 \mathrm{~h}$ after injection. Statistical analysis included one-way ANOVA (A, B, C, D and E) or two-way ANOVA for repeated measures (F) followed by Tukey HSD. Results are presented as mean \pm S.E.M. of either absolute quantities or $\%$ of control calculated from the absolute copy number of mRNA or absolute numbers. Statistical difference was accepted when $P \leq 0.05$ compared to control levels. ${ }^{*} P \leq 0.05, * * P \leq 0.01$. 
A
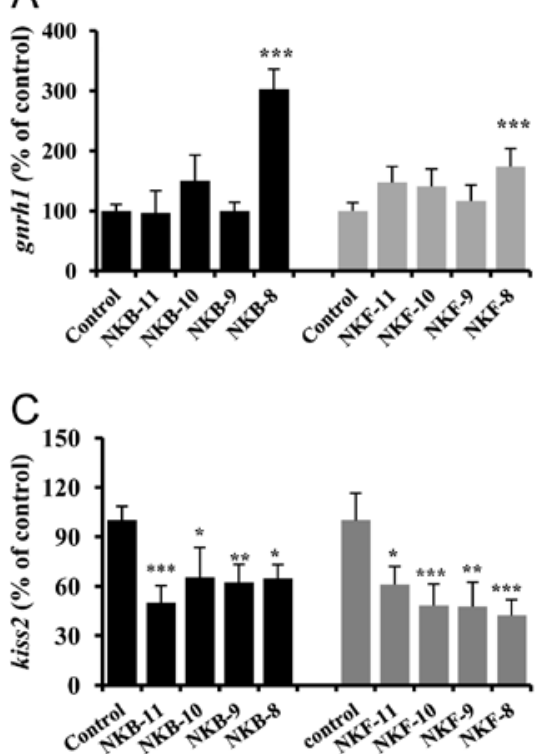

E

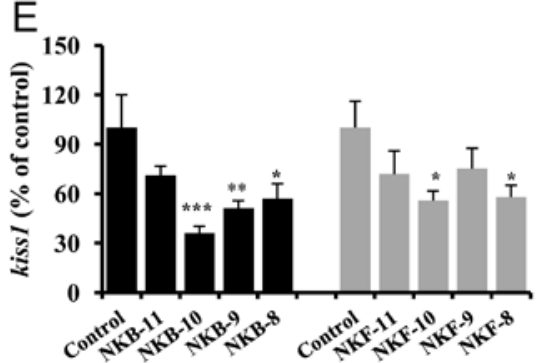

B

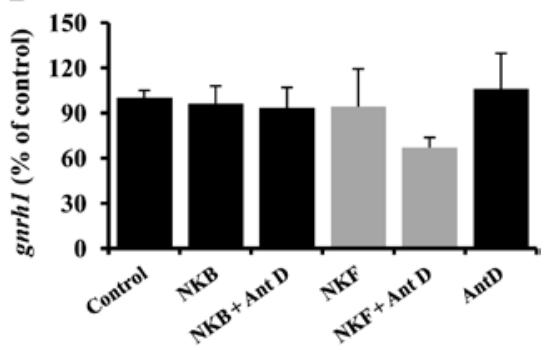

D

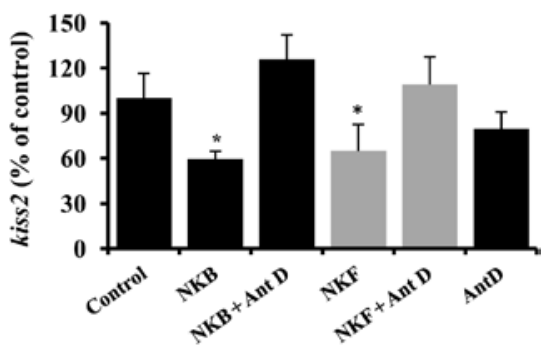

F

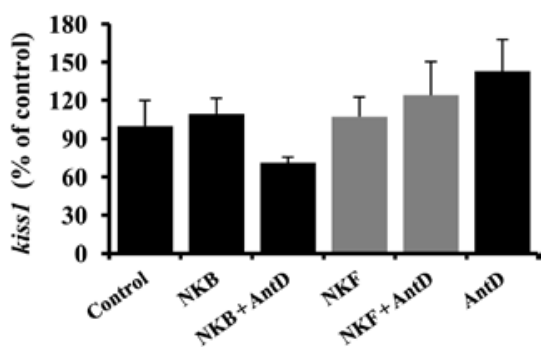

Figure 3

$\mathrm{Nkb}$ and Nkf effect on kisspeptins and Gnrh1 in brain slices in vitro. The experiments used precociously spermiating males. The effect of different concentrations of $\mathrm{Nkb}$ (black bars) and Nkf (grey bars) on the expression of (A) gnrh1, (C) kiss2 and (E) kiss1. The effect of AntD (10 nM) in the presence of $10 \mathrm{nM} \mathrm{Nkb}$ (black bars) or Nkf (grey bars) or AntD alone on (B) gnrh1 expression, (D) kiss2 and (F) kiss1. Results are presented as mean + S.E.M. of $\%$ of control levels obtained from the absolute copy number of mRNA. Statistical difference was accepted when $P \leq 0.05$ compared to control levels. ${ }^{*} P \leq 0.05$, $* * P \leq 0.01, * * * P \leq 0.005$
The effect of $\mathrm{Nkb}$ and $\mathrm{Nkf}$ on Lh and Fsh secretion from pituitary cells in vitro

Lh levels in the medium were augmented with 1 and $10 \mathrm{nM} \mathrm{Nkb}$ and $10 \mathrm{nM} \mathrm{Nkf}$ by $200 \%$ and $250 \%$ of control, respectively (Fig. 4A). Fsh levels in the medium increased in a dose-dependent manner starting at $0.1 \mathrm{nM}$ by 2 - and 5 -fold, respectively (Fig. 4B). No change was recorded in $l h b$ or $f s h b$ transcript levels (Fig. 4C and D).

\section{The effect of AntD on the HPG axis in vivo}

To test whether Nkb/Nkf is crucial to the spawning process, spermiating STB males, at the time of spawning (mid-April), were treated with microspheric implants at doses of 0,5 or $50 \mu \mathrm{g} / \mathrm{kg}$ BW AntD for 10 days. AntD, at $50 \mu \mathrm{g} / \mathrm{kg} \mathrm{BW}$, upregulated kiss 2 mRNA levels by $\sim 3$ times the control (Fig. 5A) and increased Gnrh1 peptide content in the pituitary by $\sim 40 \%$ compared to that in control levels (Fig. 5D). However, AntD had no effect on the expression of gnrh1 and kiss1 (Fig. 5B and C). A notable increase in the expression of $l h b$ and $f s h b$ was observed in both AntD treatments (Fig. 6A). Although the increase in $l \mathrm{hb}$ mRNA levels ranged between 2 and 4 times, fsh $b$ mRNA displayed a marked increase of 10 times the control levels (Fig. 6B). Lh and Fsh plasma levels were measured immediately before and 10 days after treatment. Although Lh levels significantly increased after 10 days in all treatments, levels in the AntD-treated fish did not differ from those of control fish (Fig. 6C). Fsh levels of the AntD-treated fish were significantly higher than those of control fish at the 10-day point (analyzed by one-way ANOVA) and also compared to the 0 time point (analyzed by paired t-test) (Fig. 6D).

No difference in milt weight was observed with any of the AntD treatments (Fig. 6E).

\section{The effect of Kiss1, Kiss2 and Kiss antagonists on tac3 expression}

The effect of kisspeptin on Tac3 was tested in two ways: (1) brain slices from precocious spermiating males were incubated with either Kiss1 or Kiss2 peptides at doses of

Published by Bioscientifica Ltd. 

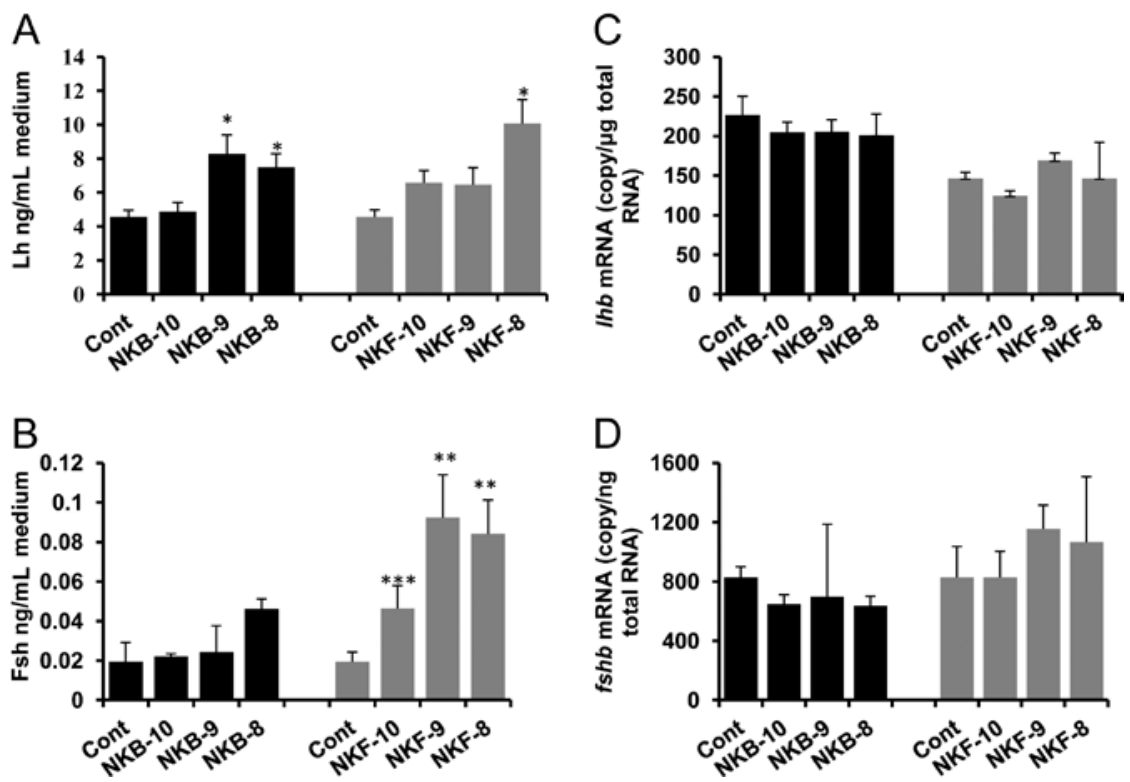

\section{Figure 4}

The effects of $\mathrm{Nkb}$ and $\mathrm{Nkf}$ on Lh and Fsh in pituitary cells in vitro. Primary pituitary cells of precociously spermiating males were treated with $0.1,1$ or $10 \mathrm{nM} \mathrm{Nkb}$ (black bars) or Nkf (grey bars) for $24 \mathrm{~h}$. (A) Lh levels in medium, (B) Fsh levels in medium, (C) Ihb mRNA levels, (D) fshb mRNA levels. Results are presented as mean \pm S.E.M. of absolute $\mathrm{ng} / \mathrm{mL}$ for protein levels in the medium. Statistical difference was accepted when $P \leq 0.05$ compared to control levels. $* P \leq 0.05, * * P \leq 0.01$.

0.5-10 nM, no effect on tac3 transcript levels was observed (Supplementary Fig. 4A); (2) when kisspeptin antagonists (Pep234 and Pep359) at doses of 5 and $30 \mu \mathrm{g} / \mathrm{kg}$ BW were administered via slow-release implants to spermiating males, no changes in tac3 mRNA levels were observed (Supplementary Fig. 4B) despite the dramatic decrease in sperm production (Zmora et al. 2015).

\section{Brain distribution and co-localization of Tac3 and Tac3r neurons}

Tac3 neuronal distribution in the brain was determined by ISH and IHC. Tac3 neurons are found in the telencephalon, in the dorsal habenula and preoptic area (Fig. 7A, B and C) and in the hypothalamic anterior tuberal nucleus (NAT) (Fig. 7D, E and F).

In the hypothalamus, Tac3 neurons in the NAT strongly innervated proximal Kiss 2 neurons in the dorsal and ventral nucleus recessus lateralis (NRL) (Fig. 8E), which in turn express tac3r (Fig. 8A, B and C). Kiss2 neuronal projections can be found around Tac3 neurons in the NAT but are relatively sparse (Fig. 8F and G).

Neurons expressing tac3 mRNA in the nucleus preopticus magnocellularis and pars parvocellularis (PMpc) are not innervated by Gnrh1 fibers (Fig. 9A). However, a few Nkb-ir fibers are observed in the vicinity of Gnrh1 somas in the nucleus preopticus parvocellularis, pars anteroventralis (NPOav) (Fig. 9B). Gnrh1 somas
A
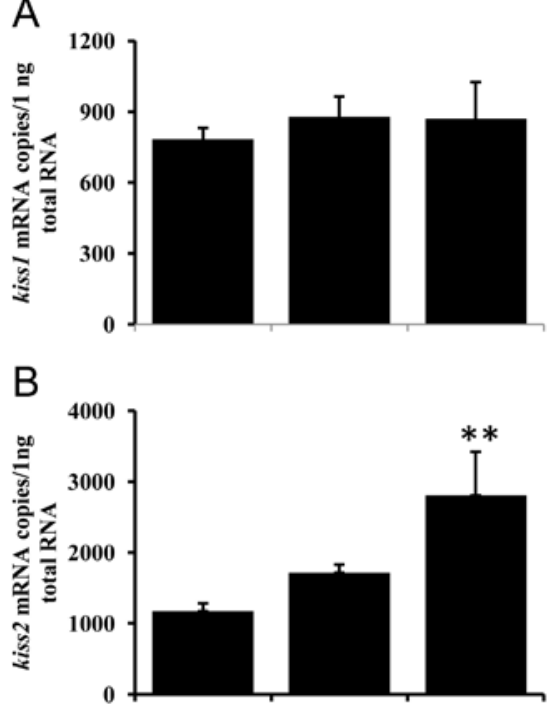

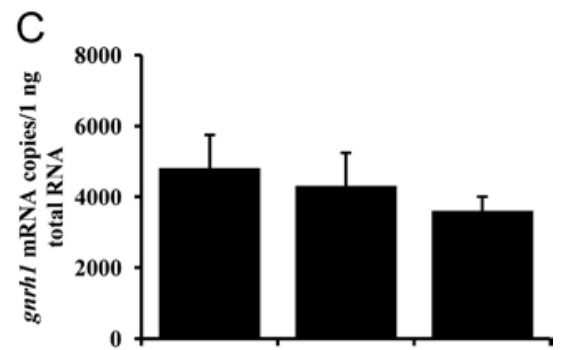

D

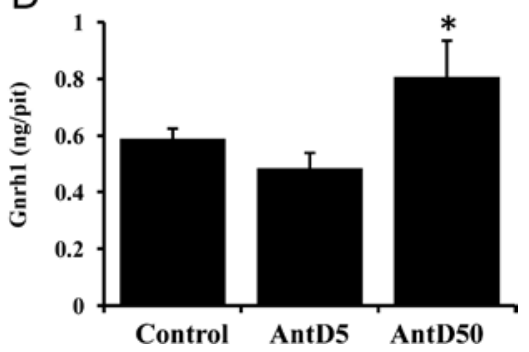

Figure 5

The effect of antagonist D on gnrh1 and kiss expression in the brain and Gnrh1 pituitary content in vivo. Fully spermiating male STB in the spawning season were treated with implants sustainably releasing AntD at doses of 0,5 or $50 \mu \mathrm{g} / \mathrm{kg} \mathrm{BW}$ ( $n=8$ per group). The effect of the treatment on the expression of (A) kiss1, (B) kiss2 and (C) gnrh1 was measured using qRT-PCR after 10 days and compared to that of the control fish. (D) Gnrh1 content in the pituitaries of the same fish was measured using a Gnrh1 decapeptide ELISA. Results are presented as mean \pm S.E.M. Statistical difference was accepted when $P \leq 0.05$ compared to control treatment levels. ${ }^{*} P \leq 0.05$, $* * P \leq 0.01$. http://joe.endocrinology-journals.org DOI: 10.1530/JOE-16-0575
๑ 2017 Society for Endocrinology Printed in Great Britain 
A
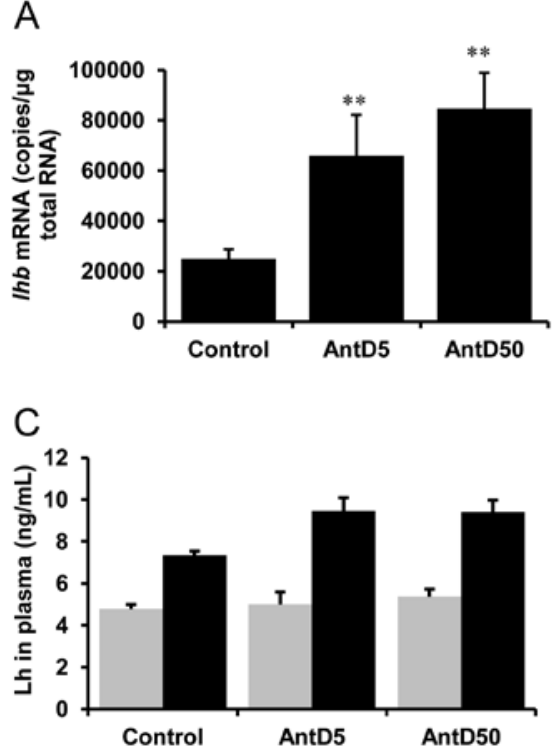

B

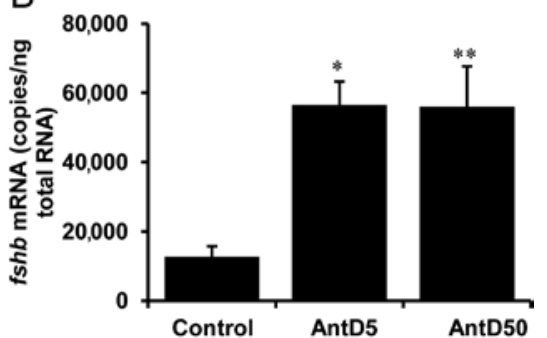

D

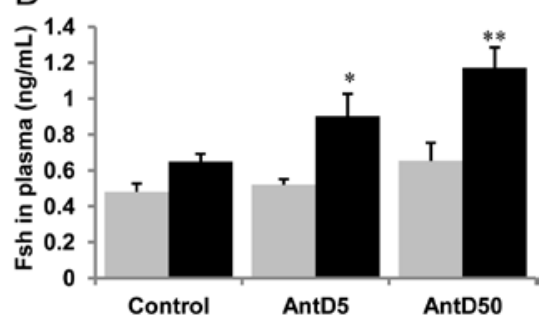

Figure 6

The effect of AntD on gonadotropin expression in the pituitary, plasma levels and milt weight in vivo. Spermiating males in the spawning season, were treated with implants sustainably releasing AntD at doses of 0,5 or $50 \mu \mathrm{g} / \mathrm{kg} \mathrm{BW}$ ( $n=8$ per group). The effect of the treatment on the expression of (A) $/ h b$ and (B) fshb, and on blood (C) Lh and (D) Fsh levels were measured using qRT-PCR or specific ELISA immediately before (grey bars) and after 10 days (black bars). (E) Post-treatment weights of stripped milt. Results are presented as mean \pm S.E.M. For hormone plasma levels, statistical difference was calculated for each treatment at 10 days compared to control levels using one-way ANOVA, and compared to 0 time for each treatment using paired $t$-test. Statistical analysis for the QRT-PCR data was performed for each treatment compared to control treatment levels and was accepted when $P \leq 0.05$. ${ }^{*} P \leq 0.05$, $* * P \leq 0.01$. do not express tac3r, whose expression is observed in neurons in the nucleus anterioris periventricularis (NAPv) and in the pituitary (Fig. 9D and E). Nkb neuronal projections innervate the pituitary and are detected in the neurohypophysis as well as Nkb-positive cells in the proximal pars distalis (Fig. 9F).

\section{Discussion}

The present study aimed at better understanding how $\mathrm{Nkb}$ and Nkf regulate reproduction in the STB. Combined neuroanatomical and induction studies in vivo and in vitro with the $\mathrm{Nkb} / \mathrm{Nkf}$ and $\mathrm{Nkb}$ antagonist, AntD, indicated that Nkb acts via kisspeptin to affect Gnrh1 neurons.

A heterologous cell culture-expressing Tac3 receptor confirmed its identity and specificity as $\mathrm{Nkb}$ receptor, which was demonstrated by the clear preference for $\mathrm{Nkb}$ and Nkf over the other neurokinins, NKA and SP. When activated, Tac3r can utilize both PKA and PKC signal transduction pathways, as also reported for other species (Biran et al. 2012, 2014, Glidewell-Kenney et al. 2014). As for the antagonists, interestingly SB222200, the widely used non-peptide mammalian NK3R antagonist
(Sarau et al. 2000, Malherbe et al. 2011), was non-potent on the STB Tac3r, suggesting that SB222200 is acting through a non-conserved region within the receptor. Of the three specific NK3R peptide antagonists, only AntD consistently and efficiently inhibited the activation of STB Tac3r (Jacoby et al. 1986).

As in other vertebrates, Gnrh1 and kisspeptin (i.e., Kiss 1 and Kiss 2 in many teleosts) are major neuropeptides controlling reproduction in the STB. Kiss1 and Kiss2 act on Gnrh1 neurons to modulate its expression and secretion in a stage-dependent manner (Zmora et al. 2012, 2014), and their neuronal subsets in the mediobasal hypothalamus display episodic appearances at the time of spawning (Zmora et al. 2014). This, and the fact that KISS1, NKB and dynorphin-A are co-expressed in the hypothalamic KNDy neurons in the arcuate-nucleus (ARC) to co-regulate GnRH1 in mammals, prompted us to examine the relationships between $\mathrm{Nkb}$, kisspeptin and Gnrh1 in the brain of the STB. Since the discovery of the KNDy neurons, scientists have wondered about the exact role of each neuropeptide and their interactions in the regulation of GnRH1 (Lehman et al. 2010, Navarro et al. 2011a, Grachev et al. 2012b, 2014, Navarro 2012, Angell \& Steiner 2015). The finding that the $\mathrm{Nkb}$ and Kiss

Published by Bioscientifica Ltd. 

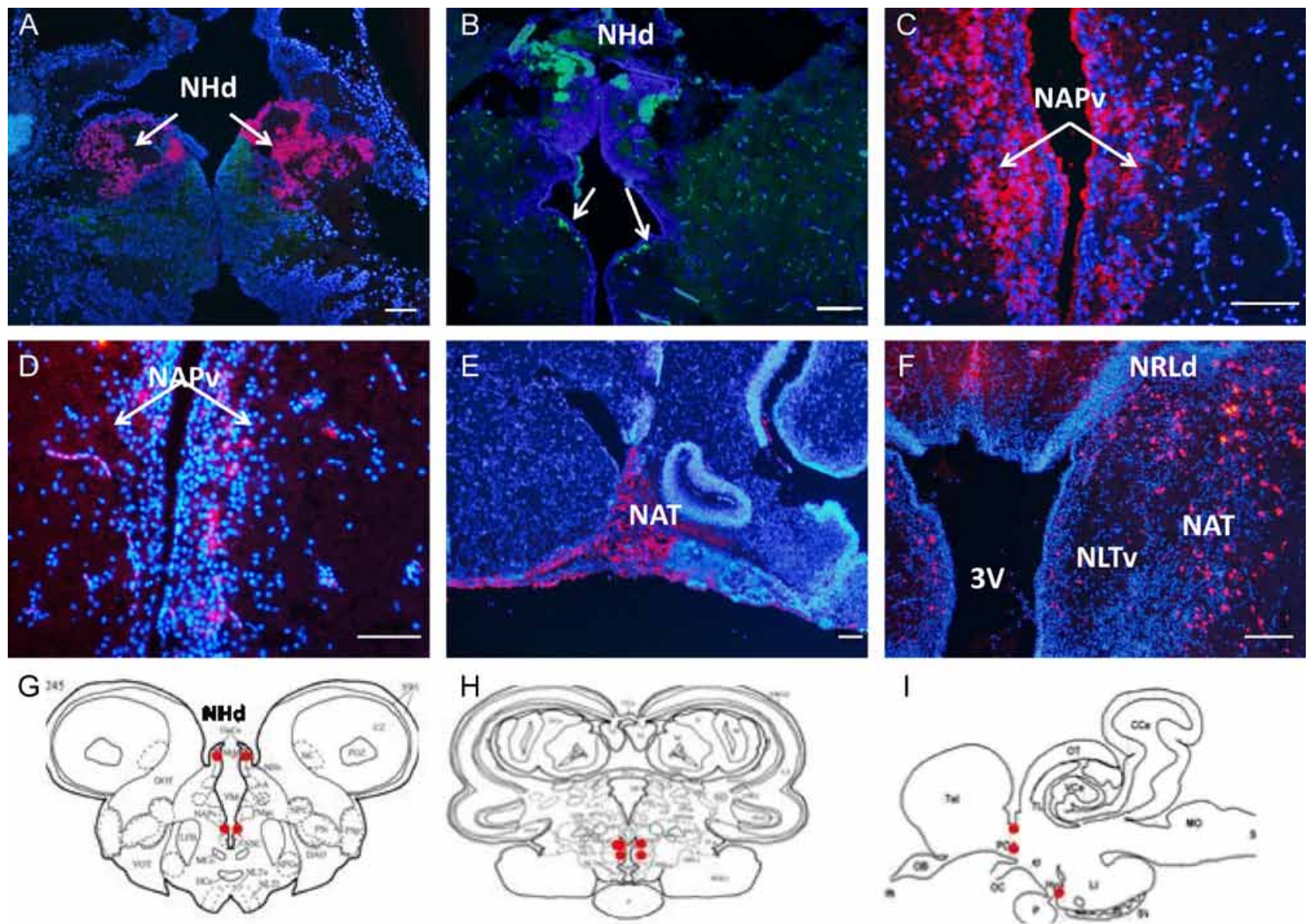

Figure 7

Distribution of tac3/Nkb-expressing neurons in reproduction-related regions in the STB brain. (A) ISH on a coronal section depicting tac3-expressing cells (red) in the dorsal habenula (NHd). (B) A similar section (tac3, green) localizing tac3-expressing neurons, using ISH, in the dorsal habenula and in the nucleus ventromedialis thalami (Vm). (C) IHC showing Nkb-containing cells (red) in the magnocellular cells in the PMpc in the nucleus anterioris periventricularis (NAPV), more ventral to the NHd and the VM. (D) ISH detecting tac3 mRNA in a tissue section sequential to (C). (E) IHC on a sagittal section demonstrating the Nkb-containing cells (red) in the hypothalamic nucleus anterior tuberis (NAT). (F) ISH on a coronal section depicting the hypothalamic NAT where tac3-expressing cells are abundant. (G) Schematic illustration of a coronal section at the preoptic region where the NHd and the NAPv are located (red dots). (H) Schematic illustration of a coronal section at the hypothalamic NAT, the NAT region is labeled with red dots. (I) A sagittal section displaying the POA, NHd and the NAT (red dots), where Nkb co-expressing cells are found.

neurons in the STB are distinct, as was found in zebrafish (Ogawa et al. 2012), suggested that this feature may be conserved in teleosts. Moreover, it provided insight into how these two neuropeptides interact and whether both regulate Gnrh1. tac3-expressing cells are widely distributed in the brain of the STB, in agreement with what is described in the goldfish and zebrafish (Ogawa et al. 2012, Qi et al. 2015). In the rostral hypothalamus, Nkb is found in the habenula and in the PMpc nucleus within the preoptic area. In the lateral hypothalamus, $\mathrm{Nkb}$ is found mainly in the NAT in the vicinity of the major Kiss2 neuronal population in the NRLd (that also co-expresses Kiss1 (Zmora et al. 2012)) and in the NRLv in the medio-basal hypothalamus. Although Gnrh1 neurons are sparsely innervated by POA Nkb fibers and do not express tac 3 or $\operatorname{tac} 3 r$, Kiss 2 neurons in the NRLd are surrounded by Nkb fibers and do express tac3r. A similar pattern is found in mammals, where KNDy neurons do not express GPR54 but express NK3R and are densely surrounded by NKB fibers that loop back to the ARC (Burke et al. 2006a, Krajewski et al. 2010, Yeo \& Herbison 2011). Indeed, the current study only detected projections of $\mathrm{Nkb}$ around the largest NRLd Kiss2 population; however, we cannot rule out weaker projections on other Kiss populations present in the brain of the STB, some of which may be temporal and stage specific. http://joe.endocrinology-journals.org DOI: 10.1530/JOE-16-0575
๑ 2017 Society for Endocrinology Printed in Great Britain 

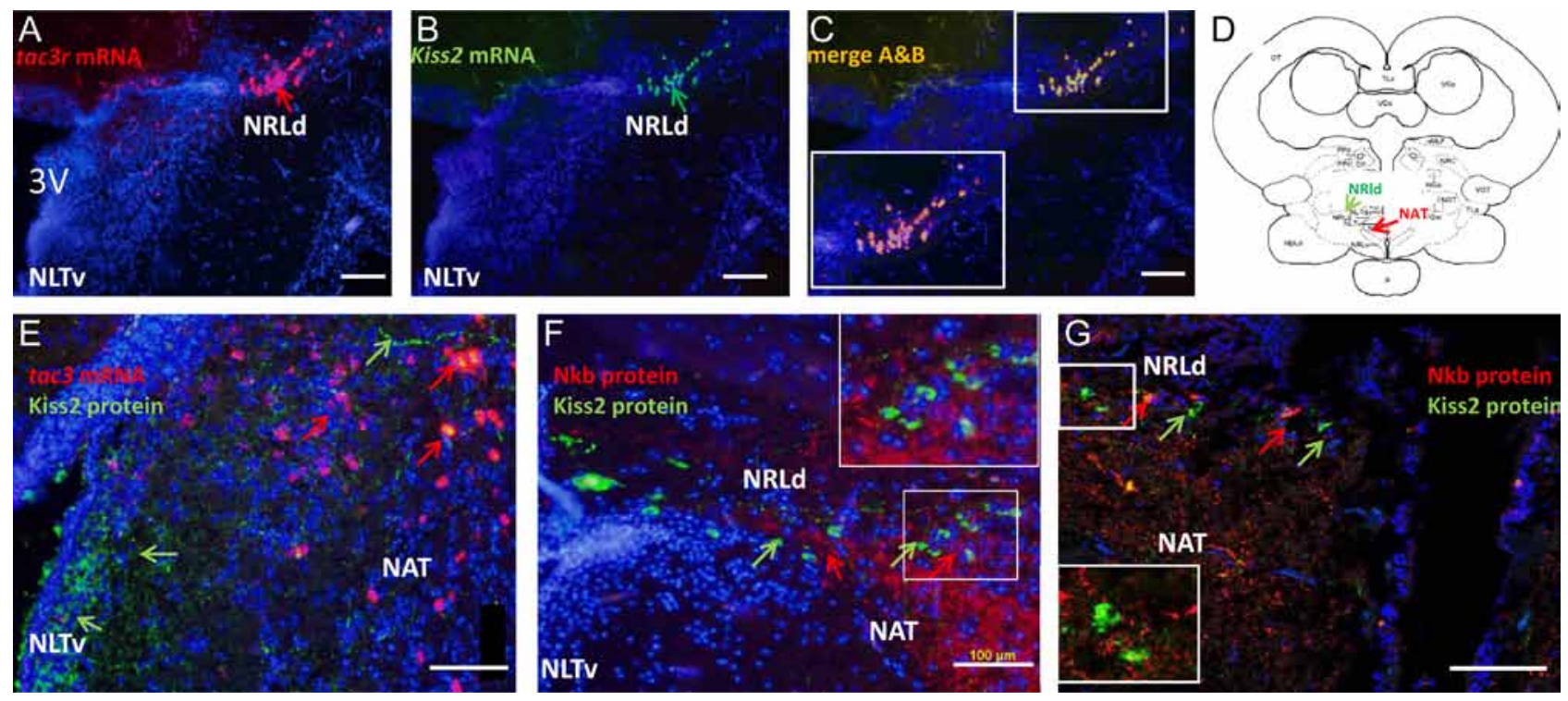

Figure 8

$\mathrm{Nkb}$ somas in the hypothalamus are localized in the vicinity of, and projected to, the major Kiss2 hypothalamic population that co-expresses Nkb receptor. (A and B) Double and combined in situ hybridization and immunocytochemistry demonstrating co-localization of (A) Nkb receptor (tac3r, red) in (B) kiss2 somas (green) in the NRLd. (C) Merged image of A and B. (D) A schematic drawing of the relevant coronal section in the hypothalamus demonstrating the close contact between the NAT and the NRId (adopted from Cerdá-Reverter et al. 2001). (E) Combined ISH (tac3, red) and IHC (Kiss2, green) used to localize tac3 somas in the NAT where a single Kiss2 fiber is observed. The majority of Kiss2 projections are seen along the NLTV. tac3-expressing neurons do not contain Kiss2. (F) Double-IHC of Kiss2 (green) and Nkb (red) depicting the NRld nucleus where a dense network of $\mathrm{Nkb}$-containing fibers surrounds Kiss2 somas. Kiss2 neurons do not contain Nkb. (G) A different section displaying double-IHC of Kiss2 (green) and Nkb (red) and depicting the NRId nucleus, where neighboring kiss2 and Nkb neurons are clearly seen separated. NRLd, nucleus recessus lateralis, pars dorsalis; NAT, nucleus anterior tuberis; NLTV, nucleus recessus nucleus lateralis tuberis, pars ventralis.

First, we examined the possibility that kisspeptin and $\mathrm{Nkb}$ affect each other. A series of brain culture experiments with kisspeptin or $\mathrm{Nkb} / \mathrm{Nkf}$ revealed that although kisspeptin does not modulate tac3 transcript levels (Supplementary Fig. 3), Nkb and Nkf modulate the expression of kiss1 and kiss2. Unlike the effect on gnrh1, that on kiss2 was consistently inhibitory in nature. Congruently, treatment with AntD upregulated kiss2 mRNA levels in the brain in vitro. The effect on kiss1 mRNA in vitro was less consistent and more sporadic than the effect on kiss2, probably due to differences in steroid levels that affect the potency of $\mathrm{Nkb/Nkf}$ (Kalra et al. 1992, Qi et al. 2015). Another possible explanation is that the NRLd subpopulation of Kiss2/Kiss1, which is in direct contact with $\mathrm{Nkb}$ neurons, contains most of the brain Kiss 2 content, whereas the Kiss1 level in these neurons is minute and consists of only a portion of the brain content (Zmora et al. 2012, 2014). This same effect was also obtained in vivo through single injections of $\mathrm{Nkb} / \mathrm{Nkf}$ and a longer treatment with AntD that downregulated and upregulated kiss expression, respectively. Combined with the co-expression of $t a c 3 r$ in kiss 2 neurons in the NRLd and the dense innervations of Nkb neurons surrounding Kiss2 somas, a negative unidirectional mode of action of $\mathrm{Nkb}$ on Kiss 2 emerges.

Next, we examined the effects of Nkb and Nkf on Gnrh1. In mammals, two different modes of action were reported for NKB: an effect on GnRH1 soma in the POA and another on GnRH1 axon terminals that induces the release of GnRH1 to the median eminence (ME) in rats (Burke et al. 2006b, Krajewski et al. 2010) and mice (Todman et al. 2005, Gaskins et al. 2013). In the STB, Gnrh1 neurons do not co-express tac3r, at least not in spermiating males, although there is an abundant presence of neurons expressing $\operatorname{tac} 3$ and $\operatorname{tac} 3 r$ in the POA that includes a few fibers in the vicinity of Gnrh1 somas. These results, together with the brain incubation studies in vitro, led us to infer that Nkb most likely does not directly regulate Gnrh1 expression in the STB. In fact, in most in vivo and in vitro trials, except on one occasion, $\mathrm{Nkb}$ and Nkf had no effect on gnrh1 transcript levels. In this single case, a dose of $10 \mathrm{nM} \mathrm{Nkb/Nkf}$ upregulated gnrh1 expression in brain cultures in vitro. This confusion is also found in other teleosts such as the Nile tilapia, in which one study reported that Nkf stimulates $\mathrm{Lh}$ and Fsh (Biran et al. 2014) and another noted that Nkf downregulated gnrh1, lhb and fshb (Jin et al. 2016). 

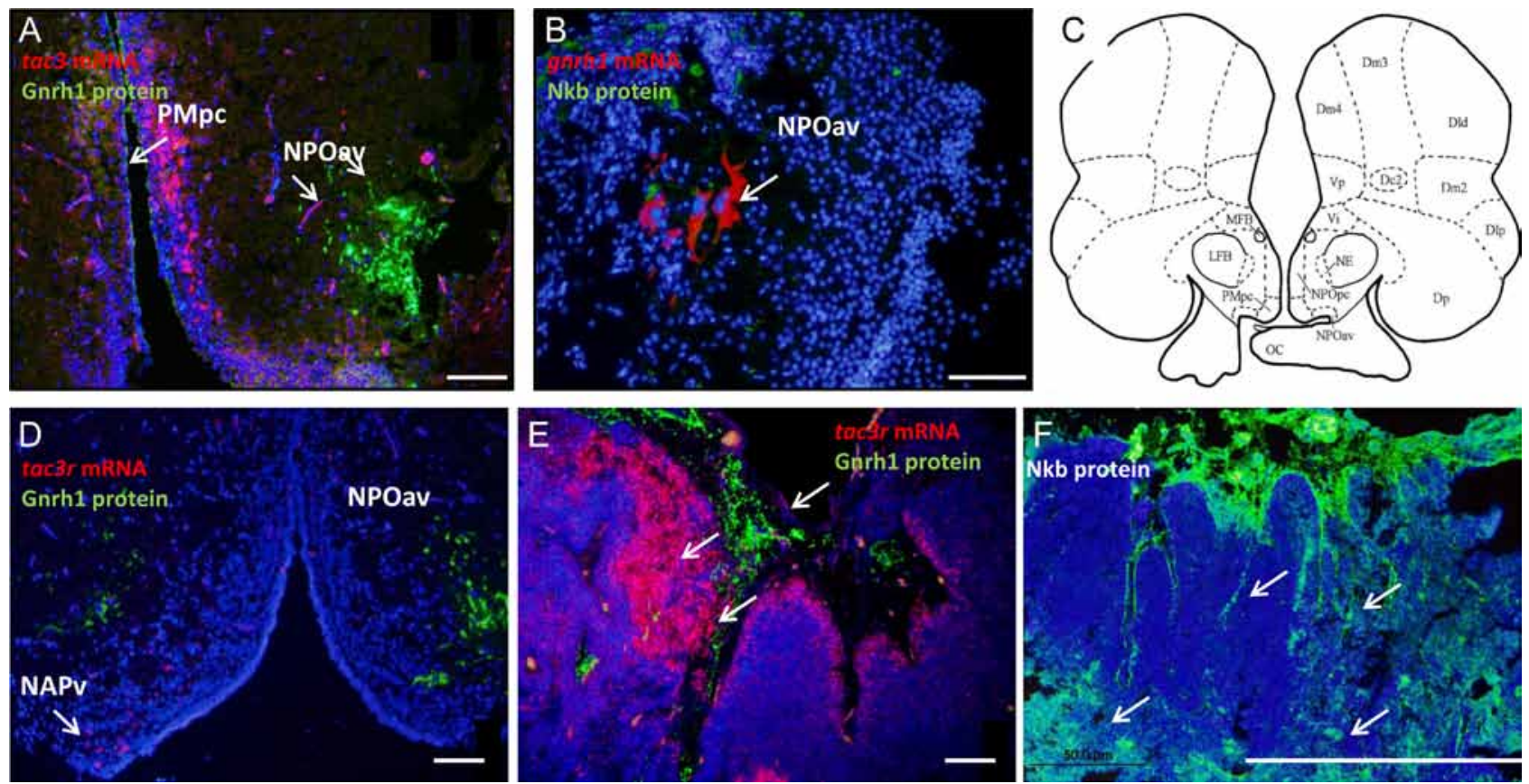

Figure 9

Nkb and Gnrh1 neuron relationships in the brain and pituitary. (A) Combined ISH (tac3, red) and IHC (Gnrh1, green) used to localize tac3-expressing neurons in the magnocellular cells in the PMpc, which is distant and is not innervated by Gnrh1 neurons in the NPOav. (B) Combined ISH (gnrh1, red) and IHC (Nkb, green) depicting the NPOav region, where gnrh1-expressing somas are located and are scarcely innervated by Nkb neuronal fibers.

(C) A schematic drawing of the relevant coronal section in the preoptic area in the brain (adopted from Cerdá-Reverter et al. 2001). (D) Combined ISH (tac3r, red) and IHC (Gnrh1, green) demonstrating that tac3r neurons are found in the NAPv and not within or in the vicinity of Gnrh1 neurons in the NPOav. (E) Combined ISH (tac3r, red) and IHC (Gnrh1, green) in the pituitary shows tac3r-expressing cells in the pituitary in the vicinity of the NH, whereas Gnrh1 neuonal projections populate the NH. (F) Nkb IHC (green) brain projections are clearly seen in the NH. Cells stained positive for Nkb are scattered throughout the pituitary including the PPD. NAPv, nucleus anterioris periventricularis; NPOav, nucleus preopticus parvocellularis, pars anteroventralis; $\mathrm{NH}$, neurohypophysis; PMpc, nucleus preopticus magnocellularis, pars parvocellularis; PPD, proximal pars distalis.

In addition, in the goldfish, Nkb upregulated gnrh3, Ih and fsh (Qi et al. 2015), results that may be attributed to variable factors, including the pharmacological dose of $\mathrm{Nkb}$ used in the goldfish $(100 \mu \mathrm{g} / \mathrm{g} \mathrm{BW})$, which is 2000 times higher than the dose used in the current study. Another possibility is differences in reproductive stagespecific actions, as seen with Kiss2 (Zmora et al. 2012) and gonadotropin-inhibiting hormone (Moussavi et al. 2014). Altogether, it is safe to conclude that in the STB, any direct action(s) of $\mathrm{Nkb}$ on the POA Gnrh1 soma is probably minor.

To truly determine the direct effect of $\mathrm{Nkb}$ on Gnrh1 release, we took advantage of the fact that fish hypothalamic neurons directly innervate the pituitary; hence, Gnrh1 content in the pituitary may be indicative of its translational levels and/or release (Holland et al. 2001). To our surprise, Nkb and Nkf systemic administration caused a decrease in Gnrh1 content in the pituitaries. This effect was not associated with the downregulation of gnrh1 mRNA in the brain, but rather with downregulation of kiss 1 and kiss2. Indeed, Kiss 1 and Kiss2 were shown to play a critical role at the time of spawning via specific and timely neuronal appearances and via their elimination by antagonists (Zmora et al. 2014, 2015). Similarly, this effect was associated with a minor decrease in gnrh1 mRNA levels and a significant decrease in Gnrh1 pituitary content (Zmora et al. 2015), indicating that disruption of normal kiss levels has a pronounced effect on Gnrh1 peptide levels rather than on its expression. Alternatively, Nkb/Nkf acts on Gnrh1 nerve terminals to release Gnrh1 and, in turn, to induce the secretion of $\mathrm{Lh}$, as reported in rats, mice and sheep (Navarro et al. 2011b, Gaskins et al. 2013, Li et al. 2015). In this scenario, decreased kiss $1 / 2$ transcript levels do not affect gnrh1 mRNA levels and as a result, Gnrh1 peptide is not replenished, whereas simultaneously, Nkb induces the release of Gnrh1, altogether resulting in lower Gnrh1 pituitary content and higher Lh plasma levels.

This study in the STB and another in tilapia demonstrate a direct effect on the pituitary by $\mathrm{Nkb}$ and Nkf that elicits both Fsh and Lh secretion from primary pituitary cultures (Biran et al. 2014). Likewise in rats, direct action of tachykinins on the pituitary stimulated http://joe.endocrinology-journals.org DOI: $10.1530 / J O E-16-0575$
๑ 2017 Society for Endocrinology Printed in Great Britain 
or inhibited LH release in intact or castrated male rats, respectively (Kalra et al. 1992). Interestingly, only Lh and Fsh secretion is augmented, whereas expression is not. This is different from the in vivo results that noted an increase in mRNA levels of $l h b$ and $f s h b$. It is noteworthy that, in many cases, the results of in vivo systemic treatment do not directly match the in vitro effects, probably due to potential feedback from other neurons (e.g., lack of neuronal connections in the brain slices preparations) and from the periphery (mainly the gonads). Another possibility is deficient paracrine interactions between the dispersed pituitary cells, insufficient to upregulate $l h$ and fsh mRNA.

As $\mathrm{Nkb}$ neuron immunoreactivity and transcript levels, as well as function, are affected by gonadal steroids (Kalra et al. 1992, Ruiz-Pino et al. 2012, Overgaard et al. 2014, Qi et al. 2015), the differences noted between the experiments may be due to gonadal steroid feedback. To test this possibility, we measured 11-ketotestosterone (11-KT, the major androgenic steroid in the striped bass) levels in the blood of the experimental fish, all of which were spermiating males, from Dec to May. 11-KT levels were similar in fish sampled in Dec, Feb and Apr-May with average levels $( \pm$ S.D.) of $8.6 \pm 1.272,8.14 \pm 1.5$ and $7.844 \pm 1.6 \mathrm{ng} / \mathrm{mL}$, respectively. Other gonadal factors, however, including different steroids and peptides can still feedback to Nkb neurons. Overall, the effect of Nkb/ $\mathrm{Nkf}$ on pituitary gonadotropins appears to be both direct and indirect. The direct effect is independent of kisspeptin and Gnrh1 neurons and comprises direct innervations and paracrine/autocrine interactions between pituitary endogenous Nkb-expressing cells (Kalra et al. 1992, Biran et al. 2014) and supported by the expression of both tac $3 r$ and tac 3 in pituitary cells, including in the proximal pars distalis. The indirect effect is exerted via kisspeptin neurons and Gnrh1 that innervate the pituitary. Together, these actions explain the puzzling stimulatory effects of both Nkb and AntD on Lh/Fsh secretion in vivo, which in theory are expected to generate opposite responses. The net result of the stimulatory effect of AntD on kisspeptin and thereby Gnrh1 overshadows its effect on the pituitary, suggesting that the hypothalamic action of Nkb is more dominant. With regard to the differential actions of Nkb and Nkf, Nkf has a more pronounced effect at the pituitary level, especially on Fsh, whereas Nkb is more potent at the brain level, inhibiting both kiss 1 and kiss2. As is seen in the receptor-binding studies, AntD had little potency in antagonizing Nkf, which together with the dominance of Nkf in the pituitary may explain the increased secretion of gonadotropins in fish treated with AntD. Interestingly in the tilapia, two forms of $t a c 3 r$ are expressed in the pituitary: $t a c 3 r b$ is expressed only in Lh gonadotropes, whereas tac3ra is expressed in both Lh and Fsh cells and is more potently activated by Nkf than by Nkb (Biran et al. 2014). This may suggest that a yet unknown second form of Tac3r, with higher preference for $\mathrm{Nkf}$ and lower affinity to AntD, is also expressed in the pituitary of the STB and may be responsible for the differential effects of Nkb and Nkf.

Finally, although kisspeptin antagonist had a remarkable effect on sperm production (Zmora et al. 2015), similar treatment in the current study with AntD resulted in no change in sperm volume. This result suggests that $\mathrm{Nkb}$ is not as crucial to spawning as kisspeptin. However, because AntD did not affect $\mathrm{Lh}$ and stimulated Fsh circulation levels, it is not surprising that there was no detrimental effect on sperm production. On the other hand, as Nkb inhibits kisspeptin, it would be interesting to test whether chronic administration of $\mathrm{Nkb}$ will indeed hinder sperm production.

In summary, in this study, we characterized the mode of action by which $\mathrm{Nkb}$ and $\mathrm{Nkf}$ exert their effects on the reproductive axis, with specific attention to their relationships with Gnrh1 and Kiss1/Kiss2 in the brain of male STB. Overall, $\mathrm{Nkb} / \mathrm{f}$ has the capacity to utilize multiple pathways to influence reproduction: negatively affecting kisspeptin neurons in the nrl and positively affecting Gnrh1 release and gonadotropin secretion. The net result of $\mathrm{Nkb} / \mathrm{f}$ administration in an experimental setting is a reduction of Gnrh1 peptide content in the pituitary and an induction of Lh and Fsh expression and secretion. However, because $\mathrm{Nkb} / \mathrm{f}$ action in the pituitary is likely paracrine/autocrine, the Nkb-Kiss2 pathway may be more dominant under natural conditions. Although the current study briefly touched upon the effects of gonadal steroids on $\mathrm{Nkb} / \mathrm{f}$ actions, this topic needs to be explored in greater detail.

\section{Supplementary data}

This is linked to the online version of the paper at http://dx.doi.org/10.1530/ JOE-16-0575.

\section{Declaration of interest}

The authors declare that there is no conflict of interest that could be perceived as prejudicing the impartiality of the research reported.

\section{Funding}

Research award (IS-4499-12CR) from the United States-Israel Binational Agricultural Research and Development (BARD) Fund.

Published by Bioscientifica Ltd. 


\section{References}

Aizen J, Kasuto H \& Levavi-Sivan B 2007 Development of a specific enzyme-linked immunosorbent assay for determining LH and FSH levels in tilapia, using recombinant gonadotropins. General and Comparative Endocrinology 153 323-332. (doi:10.1016/j. ygcen.2007.04.004)

Almeida TA, Rojo J, Nieto PM, Pinto FM, Hernandez M, Martín JD \& Candenas ML 2004 Tachykinins and tachykinin receptors: structure and activity relationships. Current Medicinal Chemistry 11 2045-2081. (doi:10.2174/0929867043364748)

Alok D, Kumar RS, Trant JM \& Zohar Y 2001 Recombinant perciform GnRH-R activates different signaling pathways in fish and mammalian heterologous cell lines. Comparative Biochemistry and Physiology Part B: Biochemistry and Molecular Biology 129 375-380. (doi:10.1016/S1096-4959(01)00325-6)

Amsteldam M, Coolen LM, Hemmerle AM, Billings HJ, Connors JM, Goodman RL \& Lehman MN 2009 Neurokinin 3 receptor immunoreactivity in the septal region, preoptic area and hypothalamus of the female sheep: colocalization in neurokinin $B$ cells of the arcuate nucleus but not in gonadotropin-releasing hormone neurones. Journal of Neuroendocrinology 22 1-12. (doi:10.1111/j.1365-2826.2009.01930.x)

Angell AE \& Steiner RA 2015 TACkling NKB's role in puberty. Endocrinology 156 1207-1209. (doi:10.1210/en.2015-1158)

Biran J, Ben-Dor S \& Levavi-Sivan B 2008 Molecular identification and functional characterization of the kisspeptin/kisspeptin receptor system in lower vertebrates. Biology of Reproduction 79 776-786. (doi:10.1095/biolreprod.107.066266)

Biran J, Palevitch O, Ben-Dor S \& Levavi-Sivan B 2012 Neurokinin Bs and neurokinin B receptors in zebrafish-potential role in controlling fish reproduction. PNAS 109 10269-10274. (doi:10.1073/ pnas.1119165109)

Biran J, Golan M, Mizrahi N, Ogawa S, Parhar IS \& Levavi-Sivan B 2014 Direct regulation of gonadotropin release by neurokinin B in tilapia (Oreochromis niloticus). Endocrinology 155 4831-4842. (doi:10.1210/ en.2013-2114)

Burke MC, Letts PA, Krajewski SJ \& Rance NE 2006a Coexpression of dynorphin and neorokinin B immunoreactivity in the rat hypothalamus: morphologic evidence of interelated function within the arcuate nucleus. Journal of Comparative Neurology 498 712-726. (doi:10.1002/cne.21086)

Burke MC, Letts PA, Krajewski SJ \& Rance NE 2006b Coexpression of dynorphin and neurokinin B immunoreactivity in the rat hypothalamus: morphologic evidence of interrelated function within the arcuate nucleus. Journal of Comparative Neurology 498 712-726. (doi:10.1002/cne.21086)

Deoraj A, Hassin S, Kumar S, Trant JM, Yu K-L \& Zohar Y 2000 Characterization of a pituitary GnRH-receptor from a perciform fish, Morone saxatilis: functional expression in a fish cell line. Molecular and Cellular Endocrinology 168 65-75. (doi:10.1016/S03037207(00)00317-8)

Gallo RV 1990 k-Opioid receptor involvement in the regulation of pulsatile luteinizing hormone release during early pregnancy in the rat. Journal of Neuroendocrinology 2 685-691. (doi:10.1111/j.1365-2826.1990.tb00465.x)

Garcia-Galiano D, van Ingen Schenau D, Leon S, Krajnc-Franken MA, Manfredi-Lozano M, Romero-Ruiz A, Navarro VM, Gaytan F, van Noort PI, Pinilla L, et al. 2012 Kisspeptin signaling is indispensible for Neurokinin B, but not glutamate, stimulation of gonadotropin secretion. Endocrinology 153 316-328. (doi:10.1210/ en.2011-1260)

Gaskins GT, Glanowska KM \& Moenter SM 2013 Activation of neurokinin 3 receptors stimulates GnRH release in a location-dependent but kisspeptin-independent manner in adult mice. Endocrinology 154 3984-3989. (doi:10.1210/en.2013-1479)
Glidewell-Kenney CA, Trang C, Shao PP, Gutierrez-Reed N, UzoOkereke AM, Coss D \& Mellon PL 2014 Neurokinin B induces c-fos transcription via protein kinase $\mathrm{C}$ and activation of serum response factor and elk-1 in immortalized GnRH neurons. Endocrinology 155 3909-3919. (doi:10.1210/en.2014-1263)

Gonzalez-Martinez D, Zmora N, Mananos E, Saligaut D, Zanuy S, Zohar Y, Elizur A, Kah O \& Munoz-Cueto JA 2002 Immuno-histochemical localization of three different prepro-GnRHs in the brain and pituitary of the European sea bass (Dicentrarchus labrax) using antibodies to the corresponding GnRH-associated peptides. Journal of Comparative Neurology 446 95-113. (doi:10.1002/cne.10190)

Goodman RL, Lehman MN, Smith JT, Coolen LM, de Oliviera CV, Jafarzadehshirazi MR, Pereira A, Iqbal J, Caraty A, Ciofi P, et al. 2007 Kisspeptin neurons in the arcuate nucleus of the ewe express both dynorphin A and neurokinin B. Endocrinology 148 5752-5760. (doi:10.1210/en.2007-0961)

Grachev P, Li XF, Kinsey-Jones JS, di Domenico AL, Millar RP, Lightman SL \& O'Byrne KT 2012a Suppression of the GnRH pulse generator by neurokinin B involves a k-opioid receptor-dependent mechanism. Endocrinology 153 4894-4904. (doi:10.1210/en.2012-1574)

Grachev P, Li XF, Lin YS, Hu MH, Elsamani L, Paterson SJ, Millar RP, Lightman SL \& O'Byrne KT 2012b GPR54-dependent stimulation of luteinizing hormone secretion by neurokinin $\mathrm{B}$ in prepubertal rats. PLOS ONE 7 e44344. (doi:10.1371/journal.pone.0044344)

Grachev P, Millar RP \& O'Byrne KT 2014 The role of neurokinin B signalling in reproductive endocrinology. Neuroendocrinology 99 7-17. (doi:10.1159/000357734)

Holland MC, Gothilf Y, Meiri I, King JA, Okuzawa K, Elizur A \& Zohar Y 1998 Levels of the native forms of GnRH in the pituitary of the gilthead seabream, Sparus aurata, at several characteristic stages of the gonadal cycle. General and Comparative Endocrinology 112 394-405. (doi:10.1006/gcen.1998.7138)

Holland MC, Hassin S \& Zohar Y 2001 Seasonal fluctuations in pituitary levels of the three forms of gonadotropin releasing hormone in striped bass, Morone saxatilis (Teleostei), during juvenile and pubertal development. Journal of Endocrinology 169 527-538. (doi:10.1677/ joe.0.1690527)

Hu G, He M, Ko WK, Lin C \& Wong AO 2014 Novel pituitary actions of TAC3 gene products in fish model: receptor specificity and signal transduction for prolactin and somatolactin $\alpha$ regulation by neurokinin B (NKB) and NKB-related peptide in carp pituitary cells. Endocrinology 155 3582-3596. (doi:10.1210/en.2014-1105)

Jacoby HI, Lopez I, Wright D \& Vaught JL 1986 Differentiation of multiple neurokinin receptors in the guinea pig ileum. Life Science 39 1995-2003. (doi:10.1016/0024-3205(86)90323-1)

Jin YH, Park JW, Kim J-H \& Kwon JY 2016 Neurokinin B-related peptide suppresses the expression of GnRH I, kiss2 and tac3 in the brain of mature female Nile tilapia, Oreochromis niloticus. Development and Reproduction 20 51-61. (doi:10.12717/DR.2016.20.1.051)

Kalra PS, Sahu A, Bonavera JJ \& Kalra SP 1992 Diverse effects of tachykinins on luteinizing hormone release in male rats: mechanism of action. Endocrinology 131 1195-1201. (doi:10.1210/en.131.3.1195)

Kinsey-Jones JS, Grachev P, Li XF, Lin YS, Milligan SR, Lightman SL \& O'Byrne KT 2012 The inhibitory effects of neurokinin B on GnRH pulse generator frequency in the female rat. Endocrinology $\mathbf{1 5 3}$ 307-315. (doi:10.1210/en.2011-1641)

Klenke U 2006 Gonadal and steroid feedback regulation of the hypothalamus-pituitary axis in striped Bass (Morone saxatilis), p 233. PhD Thesis. College Park, MD, USA: University of Maryland.

Krajewski S, Anderson MJ, Iles-Shih L, Chen KJ, Urbanski HF \& Rance NE 2005 Morphologic evidence that neurokinin B modulates gonadotropin-releasing hormone secretion via neurokinin 3 receptors in the rat median eminence. Journal of Comparative Neurology 489 372-386. (doi:10.1002/cne.20626)

Krajewski SJ, Burke MC, Anderson MJ, McMullen NT \& Rance NE 2010 Forebrain projections of arcuate neurokinin B neurons http://joe.endocrinology-journals.org

DOI: 10.1530/JOE-16-0575
() 2017 Society for Endocrinology Printed in Great Britain 
demonstrated by anterograde tract-tracing and monosodium glutamate lesions in the rat. Neuroscience 166 680-697. (doi:10.1016/j. neuroscience.2009.12.053)

Lehman MN, Coolen LM \& Goodman RL 2010 Minireview: kisspeptin/ neurokinin B/dynorphin (KNDy) cells of the arcuate nucleus: a central node in the control of gonadotropin-releasing hormone secretion. Endocrinology 151 3479-3489. (doi:10.1210/en.2010-0022)

Levavi-Sivan B, Bloch CL, Gutnick MJ \& Fleidervish IA 2005 Electrotonic coupling in the anterior pituitary of a teleost fish. Endocrinology 146 1048-1052. (doi:10.1210/en.2004-1415)

Levavi-Sivan B, Bogerd J, Mananos EL, Gomez A \& Lareyre JJ 2010 Perspectives on fish gonadotropins and their receptors. General and Comparative Endocrinology 165 415-437. (doi:10.1016/j. ygcen.2009.07.019)

Li Q, Millar RP, Clarke IJ \& Smith JT 2015 Evidence that neurokinin B controls basal gonadotropin-releasing hormone secretion but Is not critical for estrogen-positive feedback in sheep. Neuroendocrinology 101 161-174. (doi:10.1159/000377702)

Malherbe P, Ballard TM \& Ratni H 2011 Tachykinin neurokinin 3 receptor antagonists: a patent review (2005-2010). Expert Opinion on Therapeutic Patents 21 637-655. (doi:10.1517/13543776.2011.56 8482)

Mananos EL, Swanson P, Stubblefield J \& Zohar Y 1997 Purification of gonadotropin II from a teleost fish, the hybrid striped bass, and development of a specific enzyme-linked-immunosorbent assay. General and Comparative Endocrinology 108 209-222. (doi:10.1006/ gcen.1997.6966)

Moussavi M, Wlasichuk M, Chang JP \& Habibi HR 2014 Seasonal effects of GnIH on basal and GnRH-induced goldfish somatotrope functions. Journal of Endocrinology 223 191-202. (doi:10.1530/JOE14-0441)

Mylonas CC \& Zohar Y 2001 Use of GnRHa-delivery systems for the control of reproduction in fish. Reviews in Fish Biology and Fisheries 10 463-491. (doi:10.1023/A:1012279814708)

Navarro VM 2012 New insights into the control of pulsatile GnRH release: the role of Kiss1/neurokinin B neurons. Frontiers in Endocrinology 3 48. (doi:10.3389/fendo.2012.00048)

Navarro VM, Gottsch ML, Chavkin C, Okamura H, Clifton DK \& Steiner RA 2009 Regulation of gonadotropin-releasing hormone secretion by kisspeptin/dynorphin/neurokinin B neurons in the arcuate nucleus of the mouse. Journal of Neuroscience 29 11859-11866. (doi:10.1523/JNEUROSCI.1569-09.2009)

Navarro VM, Castellano JM, McConkey SM, Pineda R, Ruiz-Pino F, Pinilla L, Clifton DK, Tena-Sempere M \& Steiner RA 2011a Interactions between kisspeptin and neurokinin B in the control of GnRH secretion in the female rat. American Journal of Physiology: Endocrinology and Metabolism 300 E202-E210. (doi:10.1152/ ajpendo.00517.2010)

Navarro VM, Gottsch ML, Wu M, Garcia-Galiano D, Hobbs SJ, Bosch MA, Pinilla L, Clifton DK, Dearth A, Ronnekleiv OK, et al. 2011 b Regulation of NKB pathways and their roles in the control of Kiss1 neurons in the arcuate nucleus of the male mouse. Endocrinology 152 4265-4275. (doi:10.1210/en.2011-1143)

Navarro VM, Ruiz-Pino F, Sanchez-Garrido A, Garcia-Galiano D, Hobbs SJ, Manfredi-Lozano M, Leon S, Sangiao-Alvarello S, Castellano JM, Clifton DK, et al. 2012 Role of neurokinin B in the control of female puberty and its modulation by metabolic status. Journal of Neuroscience 32 2388-2397. (doi:10.1523/JNEUROSCI.4288-11.2012)

Ogawa S, Ramadasan PN, Goschorska M, Anantharajah A, Ng KW \& Parhar IS 2012 Cloning and expression of tachykinins and their association with Kisspeptins in the brains of zebrafish. Journal of Comparative Neurology 520 2991-3012. (doi:10.1002/cne.23103)

Overgaard A, Ruiz-Pino F, Castellano JM, Tena-Sempere M \& Mikkelsen JD 2014 Disparate changes in kisspeptin and neurokinin B expression in the arcuate nucleus after sex steroid manipulation reveal differential regulation of the two KNDy peptides in rats. Endocrinology $\mathbf{1 5 5}$ 3945-3955. (doi:10.1210/en.2014-1200)

Qi X, Zhou W, Li S, Liu Y, Ye G, Liu X, Peng C, Zhang Y \& Lin H 2015 Goldfish neurokinin B: cloning, tissue distribution, and potential role in regulating reproduction. General and Comparative Endocrinology 221 267-277. (doi:10.1016/j.ygcen.2014.10.017)

Ramaswamy S, Seminara SB \& Plant TM 2011 Evidence from agonadal juvenile male rhesus monkey (Macaca mulatta) for the view that the action of neurokinin B to trigger gonadotropin releasing hormone release is upstream from the kisspeptin receptor. Neuroendocrinology 94 237-245. (doi:10.1159/000329045)

Ruiz-Pino F, Navarro VM, Bentsen AH, Garcia-Galiano D, SanchezGarrido MA, Ciofi P, Steiner RA, Mikkelsen JD, Pinilla L \& TenaSempere M 2012 Neurokinin B and the control of the gonadotropic axis in the rat: developmental changes, sexual dimorphism, and regulation by gonadal steroids. Endocrinology 153 4818-4819. (doi:10.1210/en.2012-1287)

Ruiz-Pino F, Garcia-Galiano D, Manfredi-Lozano M, Leon S, SanchezGarrido A, Roa J, Pinilla L, Navarro VM \& Tena-Sempere M 2014 Effects and interactions of tachykinins and dynorphin on FSH and LH secretion in developing and adult rats. Endocrinology 156 576-588. (doi:10.1210/en.2014-1026)

Sandoval-Guzman T \& Rance NE 2004 Central injection of senktide, an NK3 receptor agonist, or neuropeptide Y inhibits LH secretion and induces different patterns of Fos expression in the rat hypothalamus. Brain Research 1026 307-312. (doi:10.1016/j. brainres.2004.08.026)

Sarau HM, Griswold DE, Bush B, Potts W, Sandhu P, Lundberg D, Foley JJ, Schmidt DB, Webb EF, Martin LD, et al. 2000 Nonpeptide tachykinin receptor antagonists. II. Pharmacological and pharmacokinetic profile of SB-222200, a central nervous system penetrant, potent and selective NK-3 receptor antagonist. Journal of Pharmacology and Experimental Therapeutics 295 373-381.

Tang R, Dodd A, Lai D, McNabb WC \& Love DR 2007 Validation of zebrafish (Danio rerio) reference genes for quantitative real-time RT-PCR normalization. Acta Biochimica et Biophysica Sinica 39 384-390. (doi:10.1111/j.1745-7270.2007.00283.x)

Todman MG, Han SK \& Herbison AE 2005 Profiling neurotransmitter receptor expression in mouse gonadotropin-releasing hormone neurons using green fluorescent protein-promoter transgenics and microarrays. Neuroscience 132 703-712. (doi:10.1016/j. neuroscience.2005.01.035)

Topaloglu AK, Reimann F, Guclu M, Yalin AS, Kotan LD, Porter KM, Serin A, Mungan NO, Cook JR, Ozbek MN, et al. 2009 TAC3 and TACR3 mutations in familial hypogonadotropic hypogonadism reveal a key role for neurokinin B in the central control of reproduction. Nature Genetics 41 354-358. (doi:10.1038/ng.306)

Wakabayashi Y, Nakada T, Murata K, Ohkura S, Mogi K, Navarro VM, Clifton DK, Mori Y, Tsukamura H, Maeda K, et al. 2010 Neurokinin $\mathrm{B}$ and dynorphin A in kisspeptin neurons of the arcuate nucleus perticipate in generation of periodic oscillation of neural activity driving pulsatile gonadotropin-releasing hormone secretion in the goat. Journal of Neuroscience 30 3124-3132. (doi:10.1523/ JNEUROSCI.5848-09.2010)

Yang JJ, Caligioni CS, Chan YM \& Seminara SB 2012 Uncovering novel reproductive defects in neurokinin B receptor null mice: closing the gap between mice and men. Endocrinology 153 1498-1508. (doi:10.1210/en.2011-1949)

Yeo SH \& Herbison AE 2011 Projections of arcuate nucleus and rostral periventricular kisspeptin neurons in the adult female mouse brain. Endocrinology 152 2387-2399. (doi:10.1210/en.2011-0164)

Zmora N, González-Martínez D, Muñoz-Cueto JA, Madigou T, MañanosSanchez E, Doste SZ, Zohar Y, Kah O \& Elizur A 2002 The GnRH system in the European sea bass (Dicentrarchus labrax). Journal of Endocrinology 172 105-116. (doi:10.1677/joe.0.1720105) http://joe.endocrinology-journals.org

DOI: 10.1530/JOE-16-0575
(C) 2017 Society for Endocrinology Printed in Great Britain 
Zmora N, Stubblefield J, Zulperi Z, Biran J, Levavi-Sivan B, MuñozCueto JA \& Zohar Y 2012 Differential and gonad stage-dependent roles of kisspeptin1 and kisspeptin2 in reproduction in the modern teleosts, Morone species. Biology of Reproduction 86 177. (doi:10.1095/ biolreprod.111.097667)

Zmora N, Stubblefield JD, Golan M, Servili A, Levavi-Sivan B \& Zohar Y 2014 The medio-basal hypothalamus as a dynamic and plastic reproduction related kisspeptin-gnrh-pituitary center in fish. Endocrinology 155 1874-1886. (doi:10.1210/en.20131894)

Zmora N, Stubblefield JD, Wong T-T, Levavi-Sivan B, Millar RP \& Zohar Y 2015 Kisspeptin antagonists reveal Kisspeptin 1 and Kisspeptin 2 differential regulation of reproduction in the teleost, Morone saxatilis. Biology of Reproduction 93 76. (doi:10.1095/biolreprod.115.131870)

Received in final form 11 February 2017

Accepted 20 February 2017
() 2017 Society for Endocrinology Printed in Great Britain
Published by Bioscientifica Ltd. 